\title{
EL ARTE PALEOLÍTICO DE SIEGA VERDE (SERRANILLO, SALAMANCA, ESPAÑA): UNA SINTÉTICA VISIÓN EN EL TRIGÉSIMO ANIVERSARIO DE SU DESCUBRIMIENTO
}

\author{
CARLOS VÁZQUEZ MARCOS ${ }^{(1)}$
}

Resumen:

\begin{abstract}
En el mes de octubre de 2018 se conmemoró el trigésimo aniversario del descubrimiento, por el arqueólogo Manuel Santonja, del primer équido Paleolítico de Siega Verde (Serranillo, Salamanca, España). Este acontecimiento científico y sociocultural, que resultó de crucial importancia en el cambio de visión preponderante sobre el arte Paleolítico y el poblamiento de la Meseta Ibérica en el Último Máximo Glacial (UMG), merecía una sucinta aportación sobre sus grafías parietales al aire libre en esta conmemoración, desde la singularidad y relevancia que tienen para la arqueología. Su inclusión en la Lista del Patrimonio Mundial de la Unesco en 2010, como ampliación de los sitios portugueses con arte rupestre que conforman el valle del Côa, al igual que el hecho de haberse convertido en uno de los referentes para el estudio de las manifestaciones artísticas paleolíticas y de las sociedades prehistóricas que las ejecutaron, confirman lo antedicho.
\end{abstract}

Palavras-chave: Paleolítico Superior, Arte rupestre, Arte al aire libre, Águeda, Patrimonio Mundial.

Abstract:

\begin{abstract}
The Paleolithic art of Siega Verde (Serranillo, Salamanca, Spain): A synthetic vision on the thirtieth anniversary of its discovery

In october 2018 commemorated the thirtieth anniversary of the discovery, by archaeologist Manuel Santonja, of the first Paleolithic equid of Siega Verde (Serranillo, Salamanca, España). This scientific and sociocultural event, which was of crucial importance in the change of the preponderant view on Paleolithic art and human settlement of the Iberian Meseta during the Last Glacial Maximum (LMG), deserves a contribution about its Palaeolithic figures, from the uniqueness and relevance they have for archeology. The inclusion in the Unesco World Heritage List in 2010, as an extension of the portuguese rock-art sites that make up the Côa Valley, as well as the fact that it has become one of the references for the study of Palaeolithic artistic manifestations and of the prehistoric societies that made them, confirm the aforesaid.
\end{abstract}

Keywords: Upper Palaeolithic, Rock Art, Open-air art, Águeda river, World Heritage.

\section{INTRODUCCIÓN}

El 17 de octubre de 2018 se conmemoró el trigésimo aniversario del descubrimiento científico, por el arqueólogo Manuel Santonja Gómez, del primer équido Paleolítico grabado de Siega Verde (BALBÍn et al. 1991; SANTONJA 1998: 50-56) (Figs. 1 y 2). Un hallazgo gráfico y arqueológico considerado, aun hoy, como uno de los más importantes del siglo XX en territorio Ibérico; conjuntamente con los primeros sitios superopaleolíticos a la intemperie que conforman el Parque Arqueológico del valle del Côa (Vila Nova de Foz Côa, Portugal) (BAPTISTA 1999, 2009, 2012; AUBRY 2002, 2006, 2009, 2015; ZILHÂO 2003; LUÍS 2008, 2012; AUBRY \& SAMPAIO 2008; BAPTISTA et al. 2008; FERNANDES 2012; REIS 2012, 2013, 2014; AUBRY et al. 2014; SANTOS 2015, 2017; SANTOS et al. 2018), desvelados en 1994 (Baptista \& Reis 2008: 149), si bien las primeras rocas prehistóricas, con motivos de la Prehistoria Reciente y de la Edad del Hierro, lo habían sido a mediados de 1982, en el sitio duriense de Vale da Casa (BAPTISTA 1983: 57).
La celebración de este histórico acontecimiento ha sido la excusa perfecta para que el autor de este texto, medite sobre los grabados inventariados y sobre lo que otros investigadores han visto y escrito sobre el primer gran sitio gráfico Paleolítico al aire libre publicado e interpretado en su conjunto por el equipo dirigido por Rodrigo de Balbín Berhmann, de la Universidad española de Alcalá (desde ahora UAH) (BALBÍN et al. 1991; ALCOLEA \& BALBÍN 2003, 2006, 2008; BALBín \& AlCOLEA 1994, 2001, 2006, 2014; BuENO et al. 2008). Se trata, por tanto, de una modesta contribución que aborda Siega Verde desde su contexto geomorfológico, localización, contenido, encuadre cronológico y relación con otros lugares gráficos en el mismo ambiente, abrigados o en cuevas, además de finalizar con una breve reflexión que espera sea una baldosa más, en el soterramiento de la insistente y engañosa imagen del arte Paleolítico asociado, únicamente, a entornos cavernarios y frecuentemente desligado de la cotidianidad de las sociedades humanas prehistóricas que lo ejecutaron (BALBÍN \& ALCOLEA 2017: 14; VÁZQUEZ MARCos \& ANGUlo CUeSTA p.p.).

${ }^{(1)}$ GIR PREHUSAL. Departamento de Prehistoria, Ha. Antigua y Arqueología. Facultad de Geografía e Historia. Universidad de Salamanca. Emails: carlosvázquezmarcos@gmail.com/ carlosvázquez@usal.es 

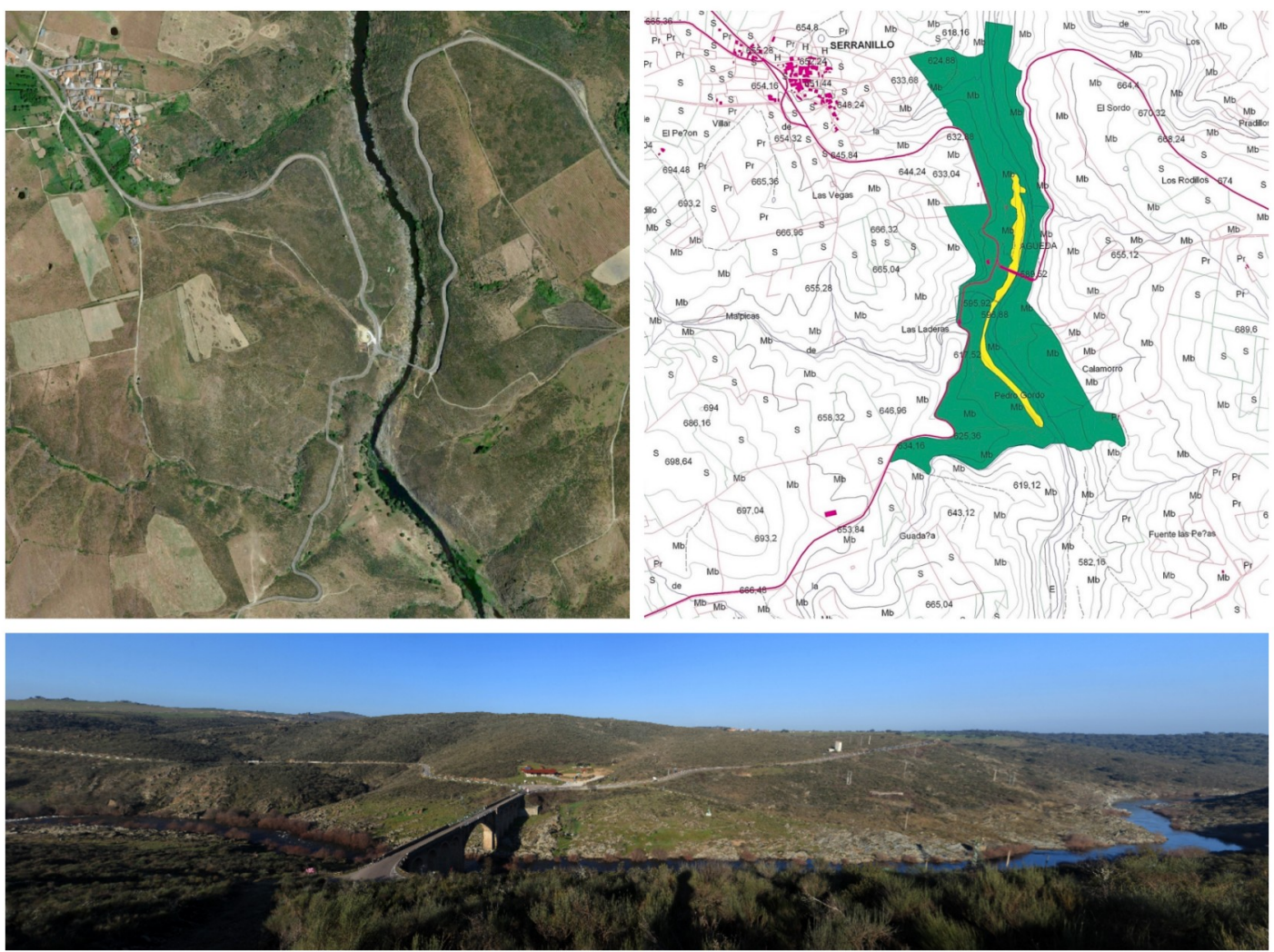

Fig. 1. Siega Verde. Fotografía $($ C Mário Reis. Mapa $@$ jcyl y Google.

Fig. 1. Fig. 1. Siega Verde. Photograph $\odot$ Mário Reis. Map $\odot$ jcyl and Google

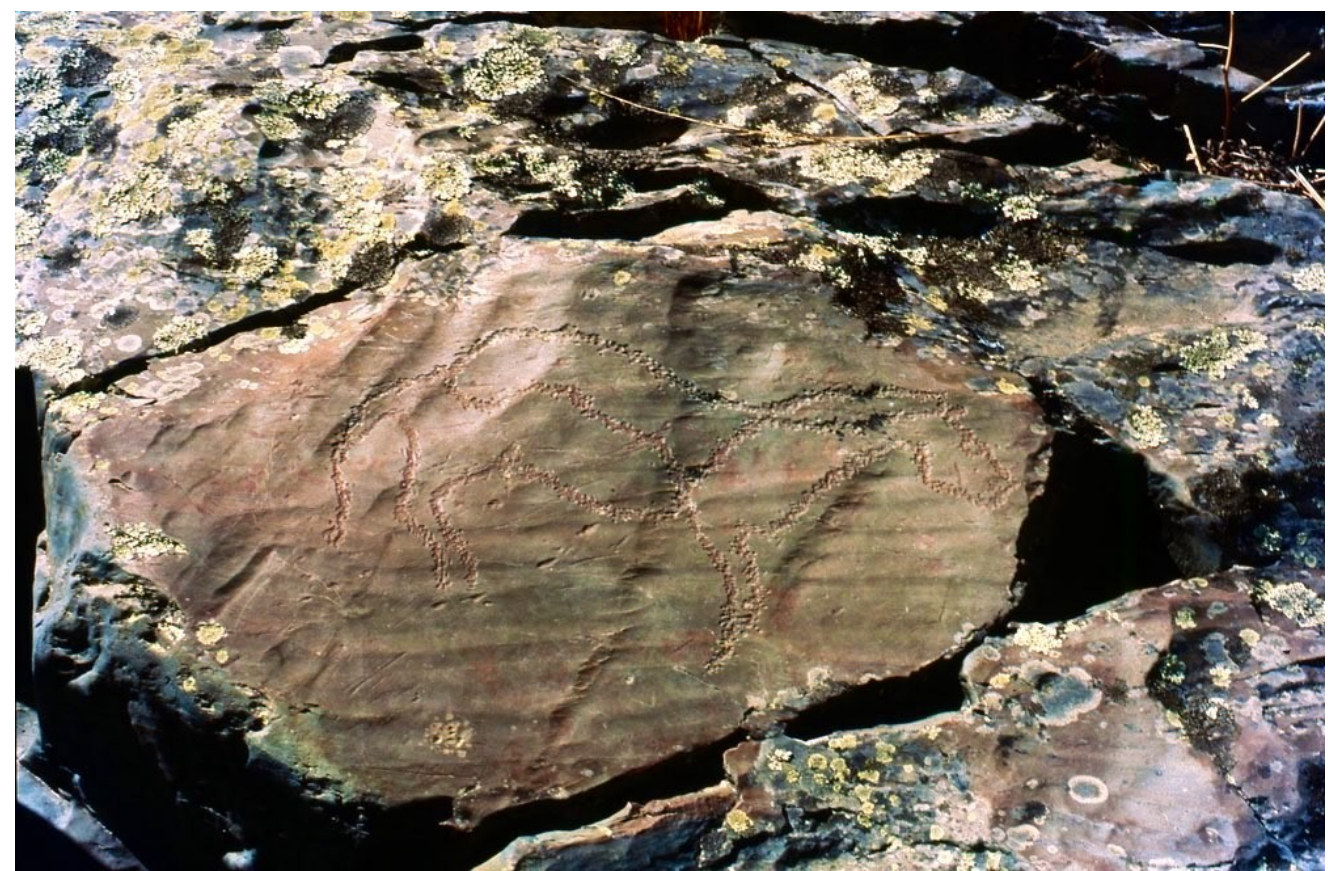

Fig. 2 Panel 3. Caballo del descubrimiento. Fotografía (C Manuel Santonja Gómez.

Fig. 2. Fig. 2. The Horse of the discovery. Photograph $($ Manuel Santonja Gómez. 
En el derrumbe de estos persistentes tópicos, tanto Siega Verde como los más de 50 sitios con arte Paleolítico en la "región" artística del Côa (REIS 2014: 33) y los restantes lugares con unidades gráficas (desde ahora UGs) paleolíticas al aire libre conocidos hasta la fecha (JORDÁ et al. 1999; AlCOLEA \& BALBÍN 2006; COLlado 2006, 2008; MARTÍNEZ 2008; SACCHI 2008; BAPTISTA 2009; BAPTISTA \& REIS 2011; BAPTISTA \& SANTOS 2013; FigUEIREDO et al. 2014; REIS \& VÁZQUEZ MARCOS 2015; SANTOS et al. 2015; GARATE et al. 2016; WELKER 2016; TEIXEIRA \& SANCHES 2017; VÁZQUEZ MARCOS \& REIS 2019) han jugado un trascendental papel.

De entre todos estos enclaves y conjuntos de sitios que conforman el también llamado "arte de la luz" (FERNÁNDEZ MORENO \& BAPTISTA 2010), remarcar aquellos que ejercieron el pionero rol en el inicial derrumbe de los paradigmas existentes, además de inexcusables para poder entender las manifestaciones paleolíticas al aire libre: Domingo García (Segovia, España) (RIPOLl \& MuNICIO 1999) y Mazouco (Freixo de Espada à Cinta, Portugal) (JORGE et al. 1981; BAPTISTA 2009: 194195). Demostrado, además, con sólidos argumentos empíricos, que estas representaciones a la intemperie no solo no fueron exiguas, sino que bien pudieron ser las mayoritarias en el Pleistoceno tardío sobre soportes parietales (BALBÍN 2008: 56; BAHN 2015: 79-91; VÁZQUEZ MARCOS \& ANGULO Cuesta p.p.) (Fig. 3).

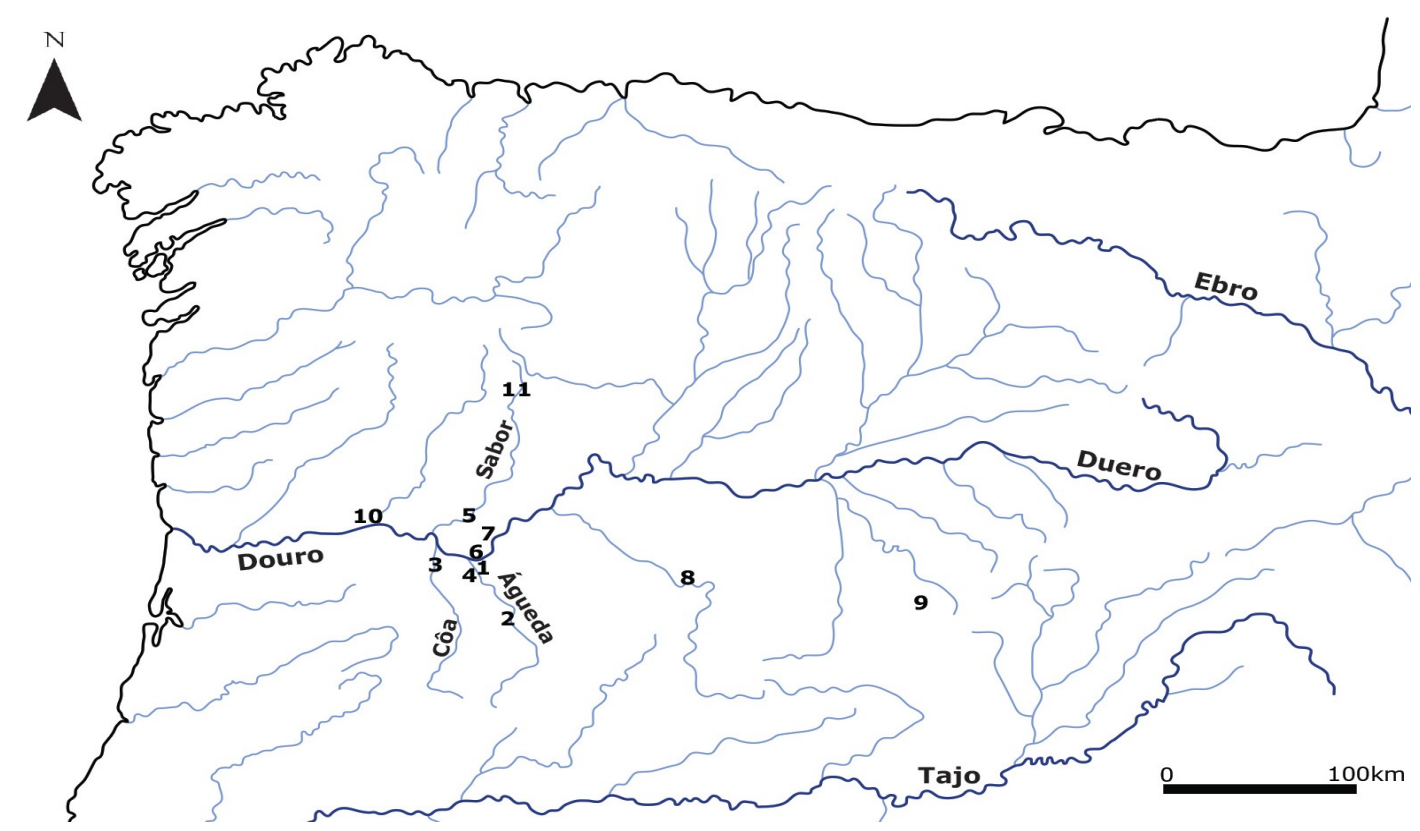

Fig. 3. Principales sitios o conjuntos de sitios, en la cuenca del Duero, con arte Paleolítico al aire libre. 1. Arroyo de las Almas; 2. Siega Verde; 3. Arte del Côa; 4. Redor do Porco; 5. Bajo Sabor (Medal, Ribeira da Sardinha y Pedra de Asma 7); 6. Fraga do Gato; 7. Mazouco; 8. La Salud; 9. Conjunto de Domingo García; 10. Tua; 11. Alto Sabor (Sampaio, Pousadouro y Fraga Escrevida). Mapa (C) Mário Reis y Carlos Vázquez Marcos.

Fig. 3. Main sites or sets of sites, in the Duero basin, with Paleolithic art in the open-air. 1. Arroyo de las Almas; 2. Siega Verde; 3. Arte del Côa; 4. Redor do Porco; 5. Bajo Sabor (Medal, Ribeira da Sardinha y Pedra de Asma 7); 6. Fraga do Gato; 7. Mazouco; 8. La Salud; 9. Conjunto de Domingo García; 10. Tua; 11. Alto Sabor (Sampaio, Pousadouro y Fraga Escrevida). Map C Mário Reis y Carlos Vázquez Marcos.

La mayoría de las miles de UGs Paleolíticas catalogadas al aire libre, preferentemente en lugares visibles con base en su prominencia e impacto visual, han sido localizadas cerca de las líneas de agua y vados fluviales (GARCÊS \& NASH 2017: 7), aunque no siempre acaece de esta forma como en Fornols (Pirineos-Orientales, Francia) o Piedras Blancas (Almería, España) (SACCHI 2008; MARTínEZ 2008). No podemos olvidar, sobre esto mismo, que muchos de los paleo-cauces de los actuales ríos, y pequeños afluentes, fueron las principales vías de comunicación para los grandes herbívoros y los grupos humanos paleolíticos de cazadores-recolectores y pescadores, como todavía lo siguen siendo para las sociedades agro-pastoriles en épocas de estío. Recalcar, además, sobre estas manifestaciones artísticas, la concepción que las aprehende como parte de un lenguaje gráfico y de transferencia simbólica e información multimodal que desempeñó, en muchos momentos, un esencial papel de marcador de los territorios recurrentemente transitados, y ocupados, además de identitario y "étnico", no siendo exclusivas de un único período cronocultural (VÁzQUEZ MARCOS \& ANGULO CUesta p.p.).

En Siega Verde, entre el final del UMG y el 
Holoceno Temprano preboreal $(\sim 19,000$ y los $\sim 9,000$ años BP) (SILVA et al. 2017; STRAus 2018: 19 ), este sistema de comunicación gráfico fue utilizado en cientos de rocas con diversos y variados mensajes figurativos, zoomorfos y antropomorfos, y signos, durante cien siglos no exentos de vacíos, que además de esencial ventaja evolutiva para nuestra especie, y quizá para otras, en momentos precedentes (HOFFMANN et al. 2018: 912-915; SLIMAK et al. 2018), fue cambiando y reinterpretándose al albur de las migraciones, los reemplazos poblacionales o los cambios medioambientales, culturales y tecnológicos (BICHO \& CASCALHEIRA 2018). Un enclave y su entorno, que al igual que otros yacimientos del interior meseteño peninsular (AlCARAZ-CASTAÑo et al. 2013; AUBRY 2015; STRAUS 2018; YRAVEDRA et al. 2018), no estuvo desprovisto de actividades humanas en períodos de rigor climático, sino de un inicial establecimiento poblacional que posteriormente será más persistente y del que este arte parietal es solo una reducido y sesgado fragmento.

\section{SIEGA VERDE: LOCALIZACIÓN Y CONTEXTO}

Siega Verde se localiza en el territorio de la pedanías de Serranillo (Villar de la Yegua), a quién pertenece la gran mayoría del yacimiento, Martillán (Villar de Argañán) y del municipio de Castillejo de Martín Viejo, en la comarca de Ciudad Rodrigo. Es aquí, en el extremo de la provincia de Salamanca, y muy próximo a los límites entre España y Portugal, en el curso medio-bajo del río Águeda y en torno al puente de La Unión, donde se puede contemplar este amplio rincón rodeado por miles de pizarras y esquistos con aptos planos de esquistosidad, sobre las que se llevaron a cabo las manifestaciones gráficas documentadas por el equipo de la UAH.

El sitio arqueológico, además de estar incluido en la Lista del Patrimonio Mundial de la Unesco como ampliación de los sitios portugueses con arte rupestre que conforman el citado valle; acaecida en la $34^{a}$ reunión celebrada en Brasilia (Brasil) entre los días 25 de julio y 3 de agosto de 2010 (BURÓN \& Del VAl ReCio 2013: 101), resulta idóneo para apreciar la relevancia y vinculación que tiene el arte rupestre con el entorno circundante (ESCUDERO 2011: 64-66), en el que fue creado y vivido, además de otorgarle vigor y permanencia (SANCHES 2017). Singularidad y significación por tanto, que recientemente ha sido ratificada, tras la concesión del distintivo de "Patrimonio Rupestre Europeo" del Itinerario Cultural del Consejo de Europa, el primero, en marzo de 2018 (FERNANDES \& VÁZQUEZ MARCOS 2018: 28-31).

Con respecto a la mayor parte de los paneles registrados y publicados hasta la fecha en Siega
Verde, resaltar que se encuentran no muy lejos del lecho del río aunque tampoco podemos olvidar, al igual que en el conjunto del arte del Côa y en otros enclaves al aire libre ya citados, que algunos han sido localizados a una distancia superior a los 40 m. de la actual línea de agua. Asimismo, es en la margen Oeste donde se sitúa la práctica totalidad de los paneles grabados dados a conocer, a lo largo del amplio kilómetro de longitud que tiene el sitio. La zona arqueológica en la que se inserta, y dividida en tres áreas para su mejor comprensión (Alcolea \& BALBÍN 2006: 62-63), es sin embargo mayor, cercana a las 44.5 Ha. (Fig. 1), encontrándose todos los grabados por debajo de los $600 \mathrm{~m}$ s.n.m (VÁzQuez MARcos \& ANGUlo Cuesta p.p.).

De su entorno geomorfológico destacar, además del abrumador predominio de las indicadas rocas metamórficas sobre las ígneas, dominantes aguas abajo, otras dos muy relevantes cuestiones: su posición en uno de los últimos vados accesibles del río Águeda antes de su desembocadura en el Duero y su especial situación en un territorio transicional entre la fosa de Ciudad Rodrigo, la penillanura y la cuenca hidrográfica de mayor superficie de la Península.

Esta fosa transcurre desde las proximidades de Salamanca hasta la freguesia portuguesa de Nave de Haver (Almeida), con una dirección NE$\mathrm{SO}$, y tiene por límites los bordes paleozoicos de la cadena hercínica (ALONSO GAVILÁN \& CANTANO MARTín 1987: 248). Asimismo, constituye un espacio físico ya ocupado desde el Paleolítico Inferior y Medio (SANTONJA 1998), y con anterioridad por tanto, a las cronologías propuestas para las evidencias gráficas de Siega Verde. Un graben que resulta de vital importancia para acceder fácilmente a la citada penillanura y a la depresión de la cuenca, al ser uno de los corredores y caminos naturales, biológicos y de comunicación preferente de la Meseta, contrariamente a lo que sucede a pocos kilómetros de este paraje, ya finalizada, donde la dificultad debió ser mayor tanto para grandes herbívoros como para las bandas de cazadoresrecolectores y pescadores en su dinámica de asentamientos, apropiación simbólica y económica del territorio y de adquisición de nuevos recursos de alimentación que les permitiera mantener su viabilidad como grupo (MATEOS CACHORRO 2010: 39).

El río Águeda es el otro gran protagonista, al estar de forma connatural relacionado con el arte parietal Paleolítico de Siega Verde. Afluente del río Duero, por su margen izquierda, tiene su nacimiento en el manantial de Puente de los Llanos, extendiéndose a lo largo de $140 \mathrm{~km}$., aproximadamente (Fuente: Confederación Hidrográfica del Duero), hasta su desembocadura en Vega Terrón. Además, en su tramo inicial en la salmantina Sierra de Gata, y muy próximo a la provincia extremeña de Cáceres, está cerca de abrazar la frontera con Portugal, 
como de hecho sucede en su tramo final. Aquí, la raya se aleja varios kilómetros y el río recorre un sinuoso trazado de Sur a Norte y casi siempre en paralelo al río Côa, con el que comparte características geomorfológicas, topográficas y litológicas, como su encajonamiento final en el Cuaternario tardío sobre el basamento Paleozoico (PÉREZ 2011: 21-25). Los últimos $40 \mathrm{~km}$ de su curso fluvial, alejados de Siega Verde, son la frontera natural entre los mencionados países, siendo la margen izquierda, en su tramo final, parte del territorio portugués. En este ambito, varios y recientes trabajos de prospección arqueológica han permitido localizar nuevas imágenes prehistóricas en ambos países, avalando la importancia que tiene la cuenca media del río Duero, y del Águeda, para la Prehistoria Ibérica (BAPTISTA \& REIS 2011; REIS \& VÁZQUEZ MARCoS 2015; VÁZQUEZ MARCOS \& REIS 2019).

\section{EL ARTE PARIETAL SUPEROPALE- OLÍTICO EN SIEGA VERDE: DESCRIP- CIÓN Y ANÁLISIS}

\subsection{Paneles y unidades}

Las UGs documentadas en Siega Verde por el equipo de las UAH son 443 (Alcolea \& Balbín 2006: 229). De ellas, 241 corresponden a animales, 165 a la temática no figurativa, o también denominada como signos (ver Apartado 3.3), 3 son antropomorfos, habiendo sido consideradas las 34 unidades restantes como figurativas zoomorfas indeterminables (BALBÍN \& ALCOLEA 2014: 602). Añadir, a esta cifra, las unidades designadas como un "estilo V" (BUENO et al. 2008; BUENO \& BALBín 2016). Estas últimas, en nuestra contabilización, ascienden a 25 unidades seguras, de las que 15 son animales, además de los signos, y que corresponderían al final del ciclo artístico Paleolítico, entre la segunda mitad del Tardiglaciar y el Holoceno temprano (ver Apartado 4), además de otros zoomorfos superopaleolíticos pendientes de publicación (VÁzQUEZ MARCos Y ANGUlO CUESTA p.p.), con un número total de UGs zoomorfas, superior a las 250 .

Todos estos grabados, ejecutados por diferentes técnicas y modalidades (ver Apartado 3. 4), se localizan en 91 paneles tanto verticales como horizontales (Fig. 2), los menos, habiendo sido agrupados en 29 conjuntos, por el equipo de la UAH, para su mejor comprensión (ALCOLEA \& BALBÍN 2006: 331-333)

\subsection{UGs figurativas: zoomorfos $y$ antropomorfos}

Los équidos, con 124 UG documentadas; de las cuales 110 son inequívocas (Figs. 2, 4, 9, 12, 13 y 14), seguidos de los uros; los bovinos más inven- tariados con 41 UGs; de las que 35 unidades son seguras (Figs. 5, 8 y 10), las ciervas y los ciervos, con al menos 18 (Figs. 4, 6 y 11), y los cápridos, con 13 (Fig. 7), son las 4 especies zoomorfas más representadas en Siega Verde, sin contabilizar las adscritas al ciclo gráfico final, entre las que se han detectado: ciervos, ciervas, cabras, peces (Fig. 16), animales indeterminables (Fig. 15) y un équido seguro (VÁZQUEZ MARCOS \& ANGUlo CUESTA p.p.).

Estas, no son las únicas UGs de animales catalogados, al haberse reconocido por el equipo de la UAH, además de los cuadrúpedos indeterminables, 17 representaciones zoomorfas entre las que están: megaloceros, osos, bisontes, renos, felinos, rinocerontes lanudos y un cánido (Fig. 8) (AlCOlEA \& BALBÍN 2006: 182). Unas especies poco habituales en el bestiario Paleolítico, excepto los bisontes, y que por las dificultades de conservación que tienen en este ambiente, especialmente los posibles bisontes y los rinocerontes lanudos publicados por el equipo de la UAH y sus principales valores anatómicos; esenciales para su adscripción, han sido muy discutidos, al poder ser confundidos con formas naturales (CORCHÓN 2006: 127), aunque en otros casos, como los renos, son incontrovertibles (Fig. 14) (VÁzQUEZ MARCos \& ANGUlO CUesta p.p.).

Sobre estas mayoritarias representaciones figurativas quisiera destacar el peso del perfil absoluto y su mayor o menor distinción; con base en la prominencia visual, ya que la técnica o las dimensiones de estos zoomorfos; con tres animales que rondan o superan el metro de longitud máxima mientras que otras unidades apenas superan los 5 $\mathrm{cm}$, junto a la coloración natural del panel; debido a los óxidos de hierro y de manganeso, rojizos y carmines de alizarina respectivamente (Figs. 4 y 5), provocarían un contraste cromático tras su ejecución totalmente diferente al que muestran en la actualidad y que haría innecesaria la pigmentación de gran parte de estos motivos. Así lo muestran los équidos con despiece ventral "en M" o el hecho de que varias de las figuras de animales, estén dirigidas a audiencias diferentes además de ubicados en espacios muy restringidos (Fig. 7). Acerca de los antropomorfos o humanoides representados en Siega Verde de forma caricaturesca, en 3 ocasiones (AlCOlEA \& BALbÍn 2006: 182); de las cuales solo una de estas UGs es segura, reseñar tanto su posición bípeda como los escasos atributos humanos identificables que en ocasiones se entremezclan con los de animales, cuasi teriántropos, siendo exclusiva la técnica de la incisión para su ejecución, con reducidas dimensiones y junto a representaciones preferentemente incisas de zoomorfos atribuibles, al igual que en la gran mayoría de los inventariados en el arte del Côa (BAPTISTA 2009: 91), al Magdaleniense Antiguo y Reciente y al final del ciclo artístico Paleolítico. 


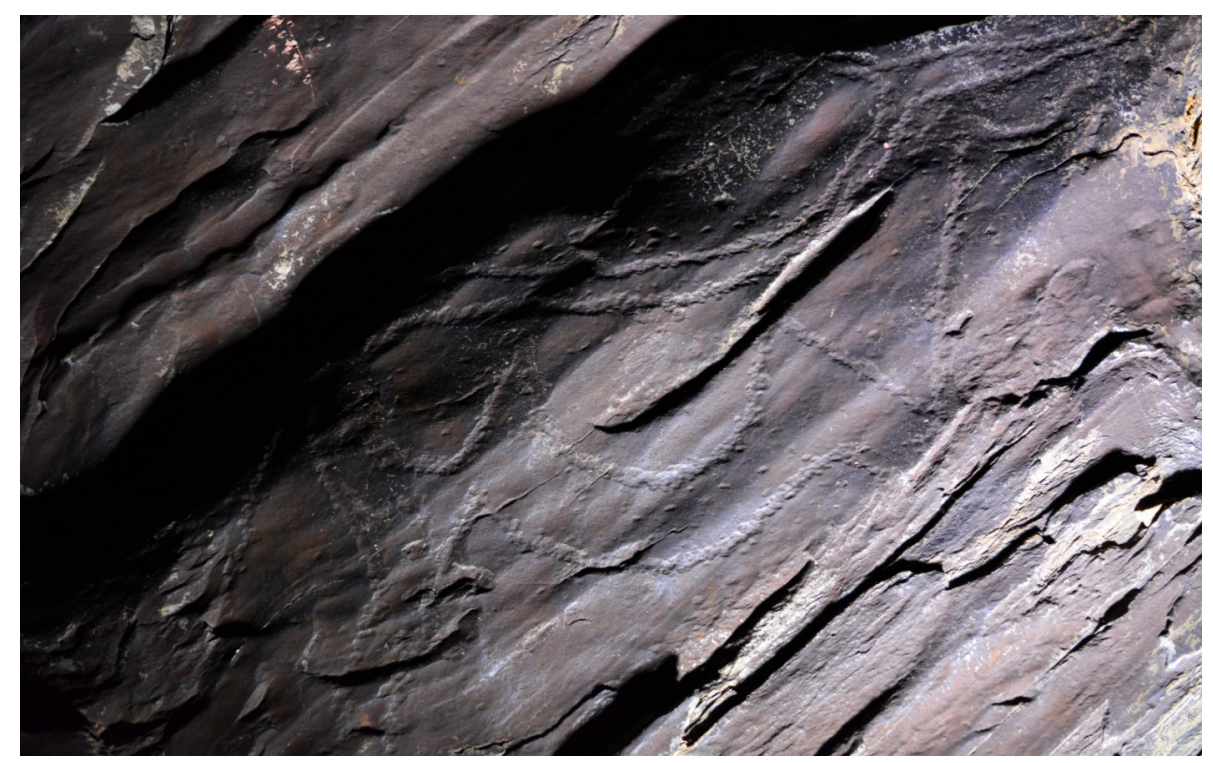

Fig. 4. Panel 46. Équido con despiece ventral "en M" y cierva. Fotografía $@$ Carlos Vázquez Marcos. Fig. 4. Panel 46. Equid with ventral "M-shape" and hind. Photograph @ Carlos Vázquez Marcos.

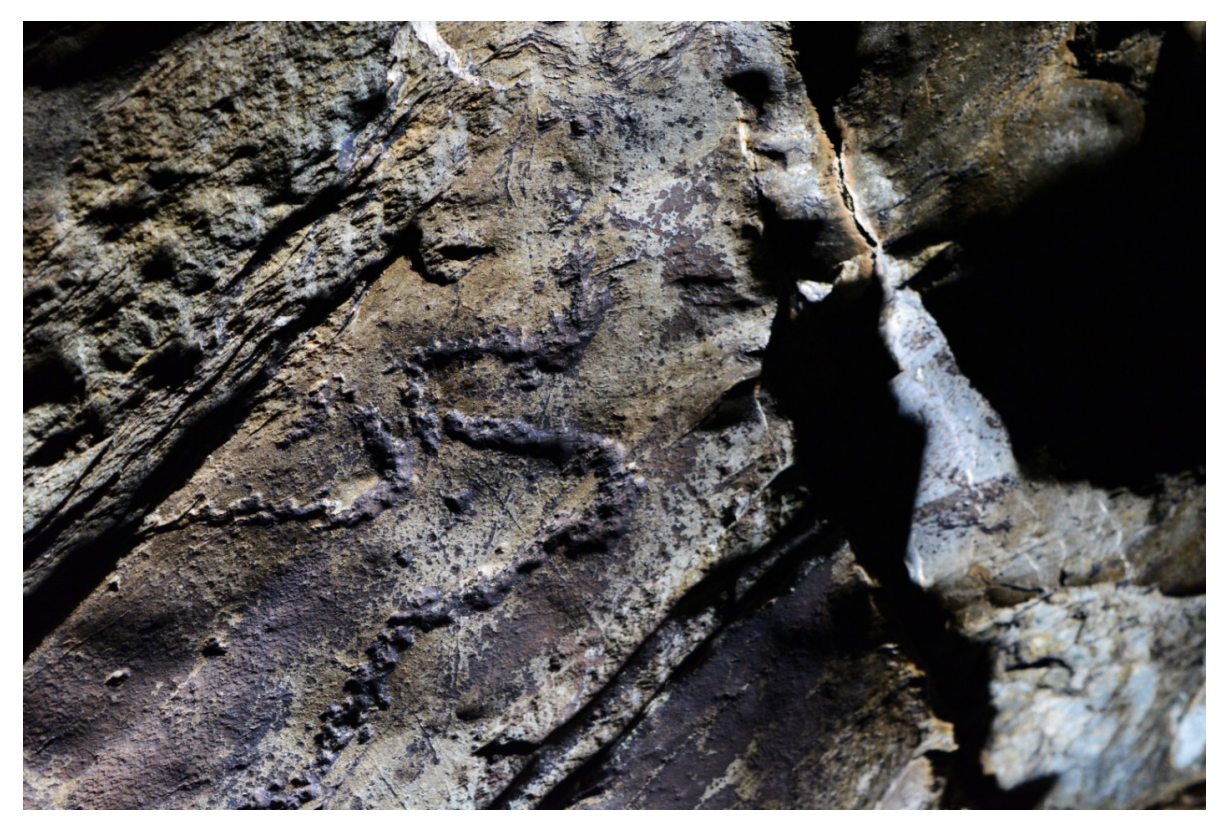

Fig. 5. Panel 46. Uro y cérvido. Fotografía (C) Carlos Vázquez Marcos.

Fig. 5. Panel 46. Aurochs and cervid. Photograph @ Carlos Vázquez Marcos. 

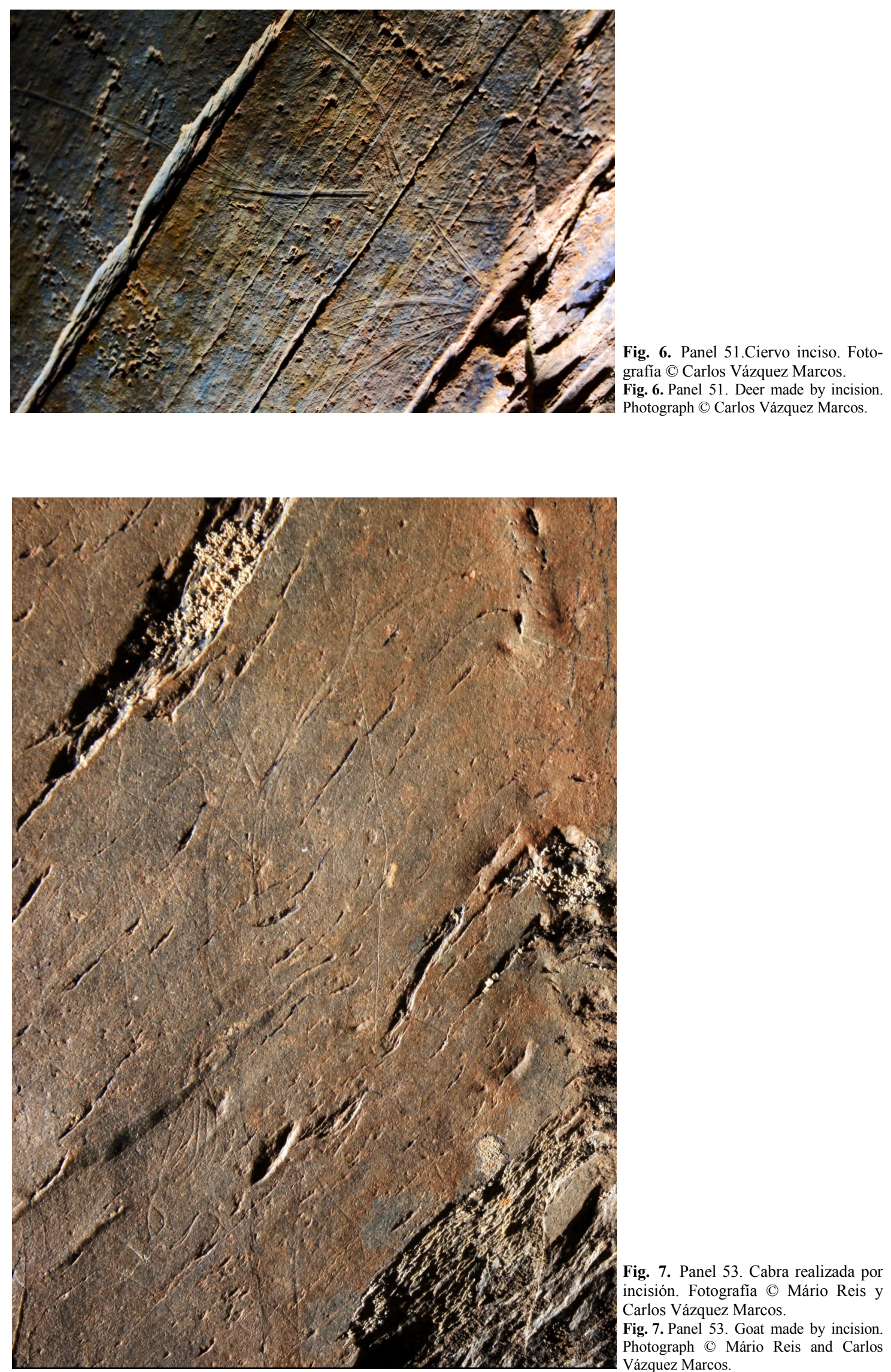

Fig. 7. Panel 53. Cabra realizada por incisión. Fotografía (C) Mário Reis y Carlos Vázquez Marcos.

Fig. 7. Panel 53. Goat made by incision.

Photograph (C) Mário Reis and Carlos Vázquez Marcos. 


\subsection{UGs no figurativas o signos}

En la catalogación realizada por el equipo de la UAH se indican 165 UGs no figurativas (ALCOLEA \& BALbín 2006: 254-260) o signos. Su complejidad, mayor que la observada en otros enclaves a la intemperie de la cuenca del Duero y del interior de la Meseta, no depende de su diversidad, sino de la originalidad y particularismo territorial y cronológico, reflejado en los escasos paralelos "regionales" o en la ausencia de varias tipologías de motivos, como los triangulares, tan frecuentes en el contexto gráfico más inmediato (CORCHÓN et al. 1996: 55; BAPTISTA 2009: 118).

Destacar aquellas UGs agrupadas dentro de la categoría de signos circulares, semicirculares, ovales o vulvares. Estas, están presentes en 13 ocasiones, mayormente piqueteadas (panel 46) y asociadas, de forma estrecha, en al menos 6 ocasiones, a bovinos (paneles 21 y 32) (Fig. 8). También son reseñables las UGs cuadrangulares y retículas, preferentemente incisas (panel 15), superpuestas o anexas a los motivos figurativos zoomorfos, o las barras y claviformes, y de producción originaria en algunos casos, en 12 ocasiones (paneles 46, 51 y 89), habiendo sido ejecutados por piqueteado además de asociados con frecuencia a los équidos y con una clara significación cronológica (Fig. 12).

Por último, citar los zigzags (panel 8), siempre incisos y superpuestos o anexos a motivos figurativos zoomorfos al igual que las múltiples puntuaciones piqueteadas intencionales, que bien podrían pertenecer a esbozos o bocetos de figuras zoomorfas sin completar, como varios de los múltiples trazos lineales y conjuntos de trazos perceptibles en la zona Central, siendo sus significados heterogéneos.

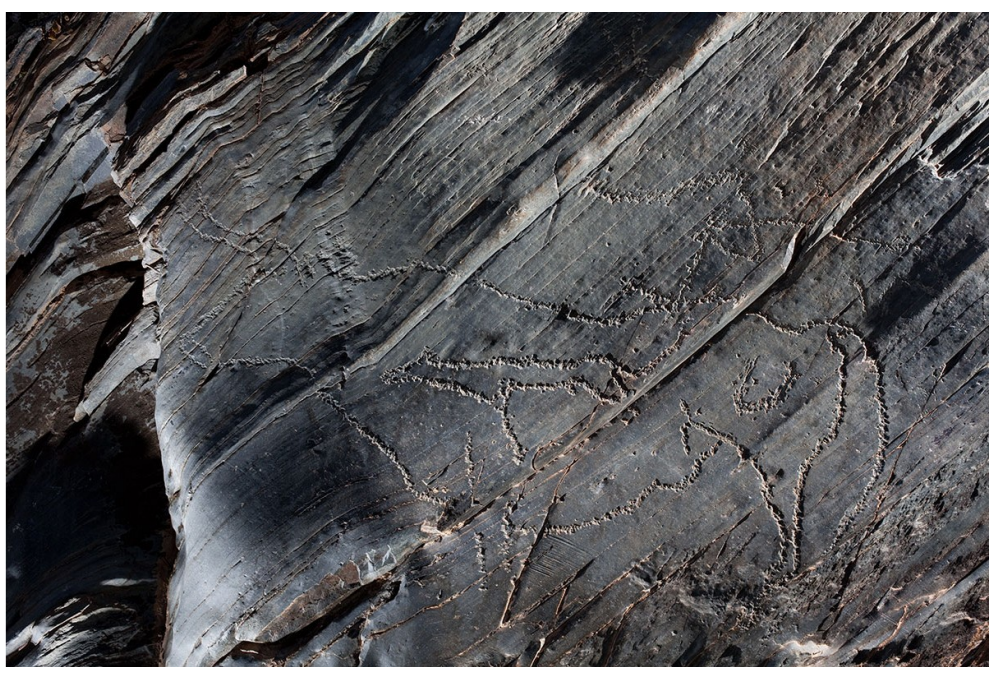

Fig. 8. Panel 32. Équidos, uros y un cánido grabados. Fotografía (C) Pedro Guimarães (pedrogima@live.com.pt) y jcyl. Fig. 8. Panel 32. Engraved equids, aurochsen and canid. Photograph (C) Pedro Guimarães (pedrogima@live.com.pt) y jcyl.

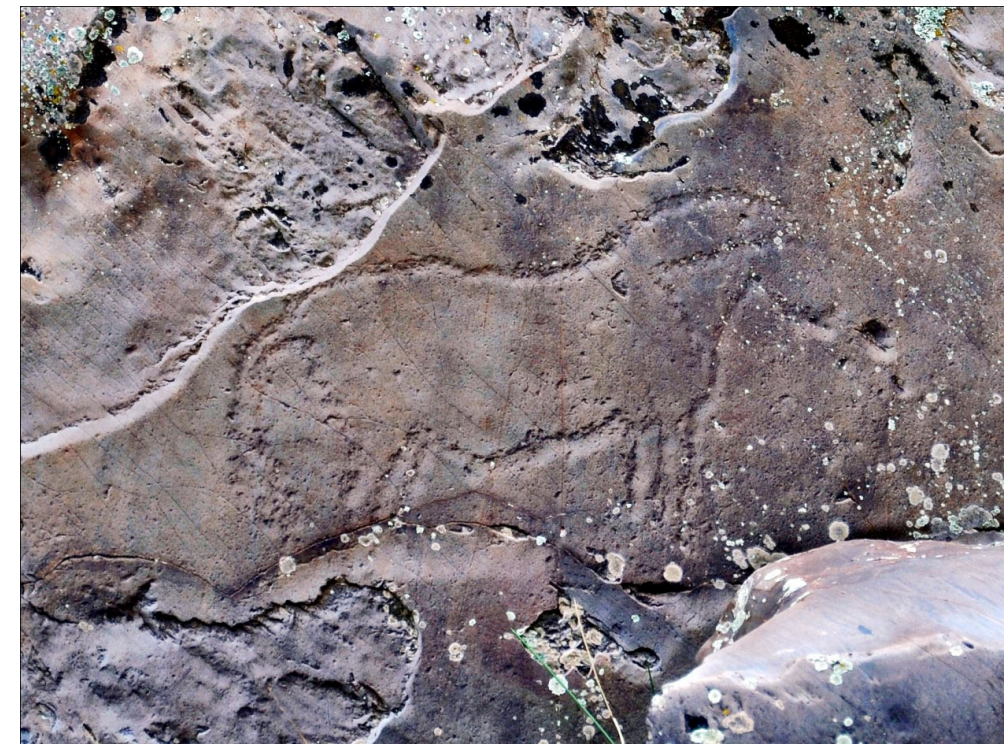

Fig. 9. Panel 85. Équido grabado por piqueteado. Fotografía (C) Carlos Vázquez Marcos y Javier Angulo Cuesta.

Fig. 9. Panel 85. Pecked equid figure. Photograph (C) Carlos Vázquez Marcos and Javier Angulo Cuesta. 


\section{4. Técnicas}

La técnica de grabado más utilizada para la ejecución de las figuras ya enumeradas, el piqueteado de contorno o contornos, directo e indirecto, corresponde al 71\% del conjunto (Figs. 2, 4, 8). La incisión, realizada en varias de las posibles modalidades conocidas en función del proceso de ejecución, aunque preferentemente en trazo único, al $27 \%$ del total (Figs. 6 y 7). La técnica de la abrasión, o grabado en trazo ancho y profundo, previo piqueteado en el caso de Siega Verde, y por encima del 1,5\% (Fig. 10), se limita a un pequeño grupo de bovinos y équidos, localizados en el centro del yacimiento y adscritos a la etapa más antigua (ALCOLEA \& BALBín 2006: 68).

Sobre la primera técnica señalada, que está presente en todos los ambientes peninsulares y euroasiáticos (BAPTISTA 2009; CLOTTES 2010: 78 81; CORCHÓN et al. 2012: 529-530; UTRILLA et al. 2012: 529), e incluso en otros continentes al aire libre con UGs Paleolíticas (HUYGE et al. 2011), apuntar, sobre la masiva utilización en Siega Verde, que se encuentra en todas las especies de animales aunque se muestra como la preferente entre los équidos y los uros. La incisión, sin embargo, será la técnica más frecuente en los ciervos y las cabras.

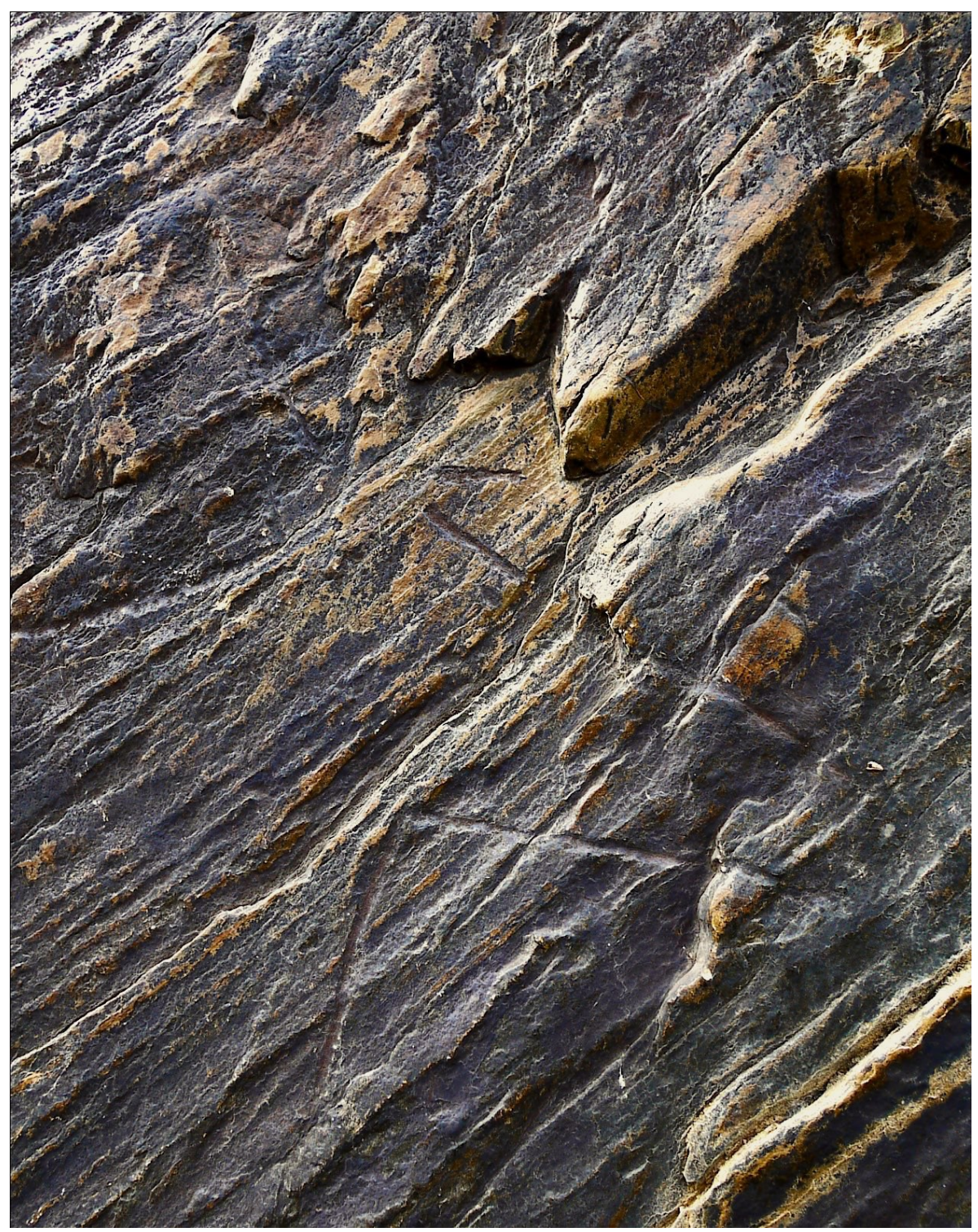

Fig. 10. Panel 4. Cabeza de uro abrasionado. Fotografía $(\subset$ Carlos Vázquez Marcos.

Fig. 10. Panel 4. Head of aurochs made by abrasion. Photograph $\odot$ Carlos Vázquez Marcos. 


\section{VINCULACIÓN CON OTROS ENCLAVES ARTÍSTICOS PALEOLÍTICOS PENÍNSULARES Y ENCUADRE CRONOLÓ- GICO}

La atribución cronológica propuesta para el conjunto de grabados del sitio, por parte del equipo de arqueólogos dirigido por Rodrigo de Balbín Berhmann, tiene su inaugural horizonte gráfico, estilos IIIII de Leroi-Gourhan, en el tecnocomplejo Solutrense (LEROI-GOURHAN 1971; ALCOLEA \& BALBÍN 2006: 68). Una primera fase gráfica escasamente representada en paneles y figuras, con la excepción de algunas UGs registradas en los paneles 4, 15, 18, 19 o 21 (Fig. 10); por citar los más relevantes, y con vigorosas e irrefutables relaciones formales, temáticas y técnicas con la etapa más arcaica o fase I del arte Paleolítico del Côa (BAPTISTA 2009: 196-207; SANTOS 2017: 338, 340-341), además de con los principales sitios cavernarios del interior peninsular con grafías pre-magdalenienses como Los Casares (Riba de Saelices, Guadalajara), La Griega (Pedraza, Segovia), La Hoz (Santa María del Espino, Guadalajara) o El Reno (Valdesotos, Guadalajara) (ALCOLEA \& BALBÍN 2006: 320; 2008: 84-86; BAPTISTA 2009: 139; RIVERO 2010: 87 y 93; ANGULO \& MORENO 2010; HERNANDO 2014: 408-410; SANTOS 2017: 336-348; VÁzQUEZ MARCOS \& ANGULO CUESTA p.p.).

En Siega Verde, esta fase tiene como principales características formales y técnicas: la monumentalidad de estas unidades zoomorfas, el área de influencia otorgada por los artistas paleolíticos a las figuras, su reconocimiento desde la margen contraria o margen Este, la abrasión o grabado en trazo ancho y profundo junto al piqueteado de contorno o contornos; como las únicas técnicas empleadas en su ejecución, o la prevalencia de los contornos y del "el arte de la silueta" (PIGEAUD 2005: 10), sobre cuantificables detalles y valores anatómicos de etapas posteriores (VÁZQUEZ MARCOS 2014, 2015, 2017; VÁZQUEZ MARCOS \& ANGULO CUESTA p.p.).

El momento de mayor densidad gráfica del yacimiento se produciría sin embargo después, entre el final del Solutrense y el Magdaleniense Inferior, estilos III avanzado-IV antiguo de Leroi-Gourhan (ALCOLEA \& BALBÍN 2006: 315 y 319), proponiendo estos mismos investigadores una cronología de entre los $\sim 18,000$ y los $\sim 15,000 / 14,000$ años BP para el cuerpo principal de los grabados (ALCOLEA \& BALBíN 2006: 319) (Fig. 11). Aquí, la coexistencia entre el piqueteado de contornos y la incisión, desde el punto de vista técnico; aun siendo la primera técnica señalada abrumadoramente dominante, el predominio de la verticalidad; sin desdeñar las figuras grabadas aprovechando paneles horizontales (Fig. 2), la mayor diversidad zoomorfa con respecto a la primera; dominando uros y équidos pero con la importante presencia de cérvidos, cabras y otras especies menos habituales en el bestiario superopaleolitico como los renos, además de tener como características formales esenciales: las alargadas y desproporcionadas cabezas en los zoomorfos, el predominando del perfil absoluto y las líneas cérvicodorsales cóncavas o rectas y de vientres convexos con exiguos rasgos o valores anatómicos grabados.

La ausencia de información numérica directa y la imposibilidad de relacionar los posibles lugares de habitación con el arte parietal inventariado en Siega Verde (BALBÍN 2008), no permite concretar un encuadre cronológico más preciso (CACHO et al. 2010). Pese a esto, recientes trabajos sobre rasgos y valores anatómicos reiterativos y de homogeneidad formal y estilística, además de ratificar las propuestas del principal equipo arqueológico de Siega Verde y su trabajo, concluyen, asimismo, sobre lo adecuado de proponer la presencia de un valioso contenido gráfico llevado a cabo en el Magdaleniense Reciente, entre los $\sim 14,500$ y los $\sim 11,500$ años BP, de algunas evidencias gráficas, figurativas zoomorfas y signos (VÁZQUEZ MARCOS 2014, 2015, 2017; SANTOS 2017: 233) (Fig. 12), en paneles situados, preferentemente, en el Centro y Norte del sitio (VÁzQuez Marcos \& ANGUlo Cuesta p.p.).

Estas dos últimas zonas muestran una considerable diversidad zoomorfa, el aumento de los cérvidos, la disminución general del tamaño de las representaciones, los relevantes despieces ventrales "en M" entre los équidos (VÁzQuez MARCos 2017) (Figs. 4 y 13), el registro de animales con "animación", los cambios en las perspectivas dominantes o el aprovechamiento más generalizado de los accidentes naturales y las formas preexistentes; aunque ya habían sido detectadas con anterioridad (FERNANDES et al. 2017), con extremidades anteriores o posteriores completas, rabos finalizados como continuación de la línea cérvicodorsal o recalcables detalles anatómicos, que en las fases precedentes habían sido raramente cuantificados como corvejones, cascos, ollares, pezuñas, ojos, sotabarbas o bocas (Fig. 7).

Por último, en los paneles 5, 8, 15 y 48, por citar algunos de los mejores ejemplos para Siega Verde; aunque no los únicos, encontraríamos una fase final caracterizada por un deliberado cambio artístico, funcional y de significados, a tenor de otros enclaves incluidos en este período cronocultural contextualizado y denominado indistintamente, en la literatura especializada, como un "estilo V" o finiglaciar (Bueno et al. 2008; Baptista 2009), Magdaleniense Final/Aziliense (SANTOS 2015: 23-24; 2017: 252 253) o Magdaleno-Aziliense (CORCHÓN et al. 1996; Reis 2014), Aziliense o finipleistocénico (AUBRY et al. 2017), Magdaleniense final/Epimagdaleniense o Epimagdaleniense (VILLAVERDE 2015), finipaleolítico (VIÑAs et al. 2012) o Postmagdaleniense (GUY 1993), y que corresponde al "arte del final del ciclo artístico paleolítico" (Figs. 15 y 16) (VÁZQUEZ MARCOS \& ANGUlo CUESTA p.p.). 


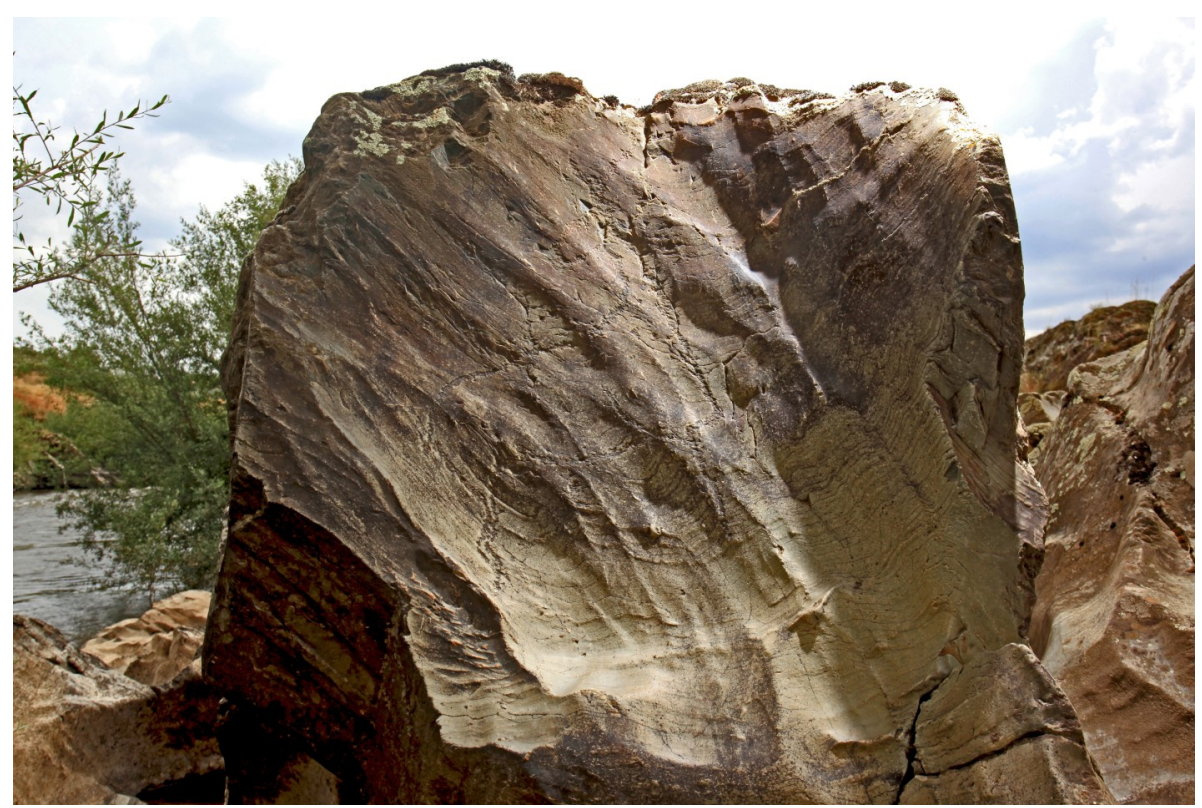

Fig. 11. Panel 23. Ciervo. Fotografía $\odot$ Mário Reis y Carlos Vázquez Marcos.

Fig. 11. Panel 23. Deer. Photograph (C) Mário Reis and Carlos Vázquez Marcos.

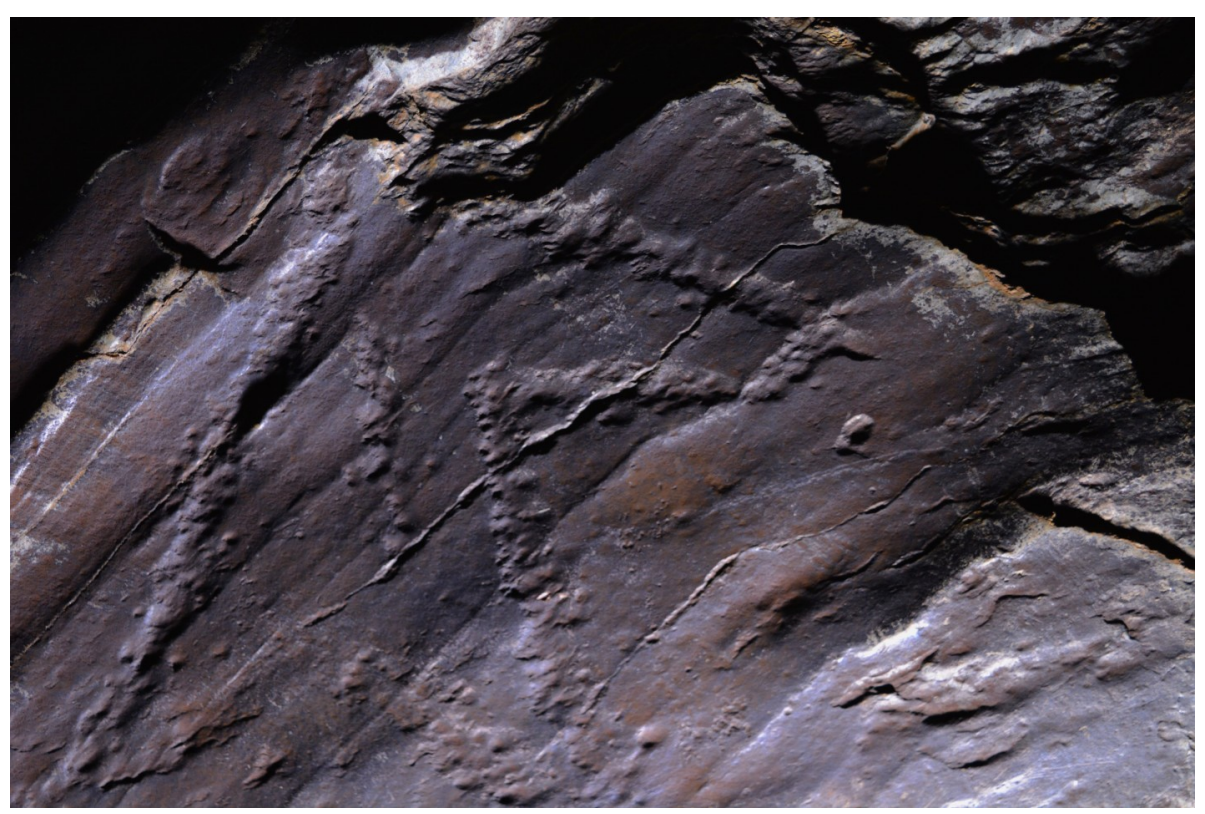

Fig. 12. Panel 46. Équido y signo claviforme. Fotografía (C) Carlos Vázquez Marcos.

Fig. 12. Panel 46. Equid and claviform sign. Photograph @ Carlos Vázquez Marcos. 


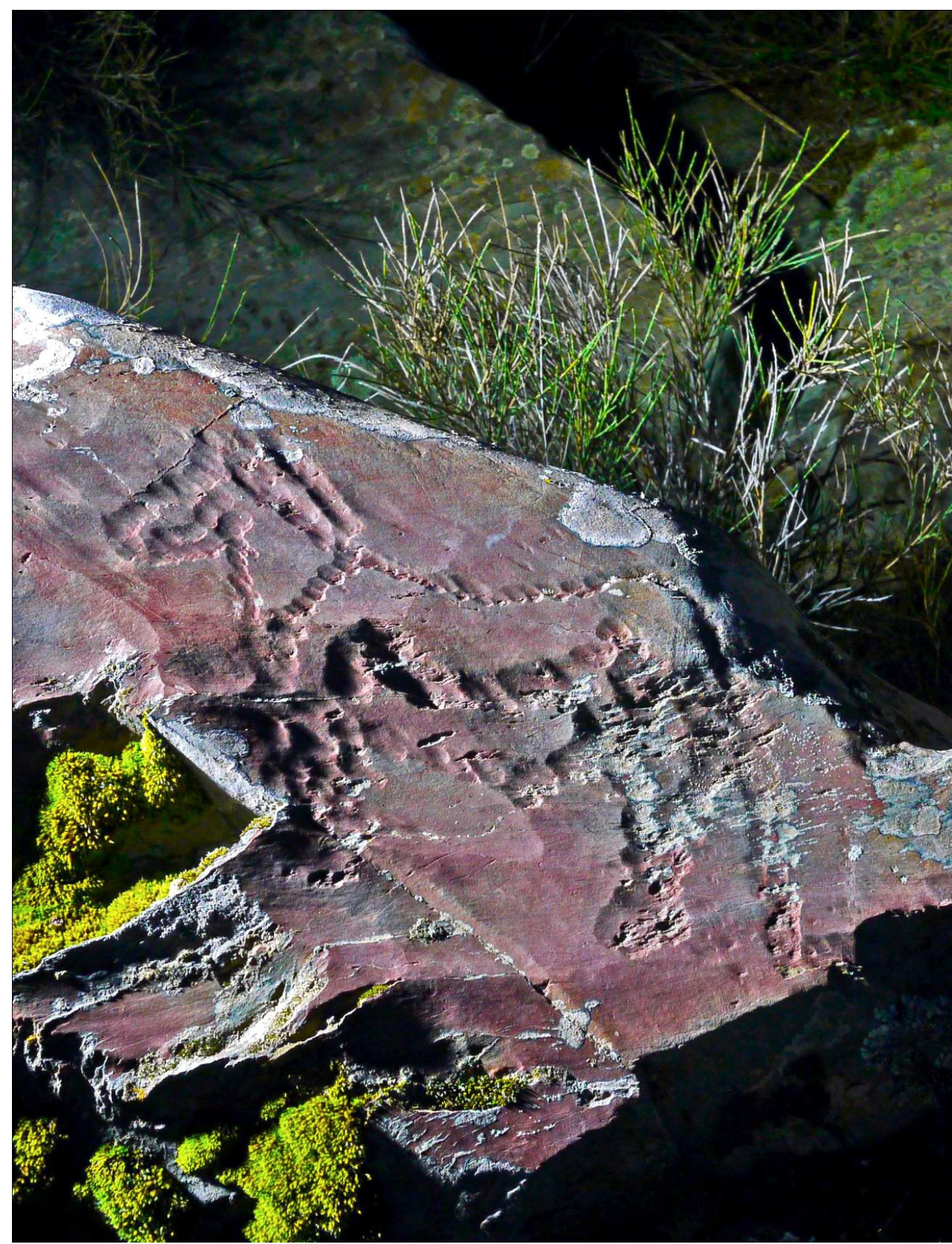

Fig. 13. Panel 74. Équido con despiece ventral "en M". Fotografía $(\mathcal{C}$ Carlos Vázquez Marcos y Javier Angulo Cuesta. Fig. 13. Panel 74. Equid with ventral "M-shape". Photograph @ Carlos Vázquez Marcos and Javier Angulo Cuesta. 


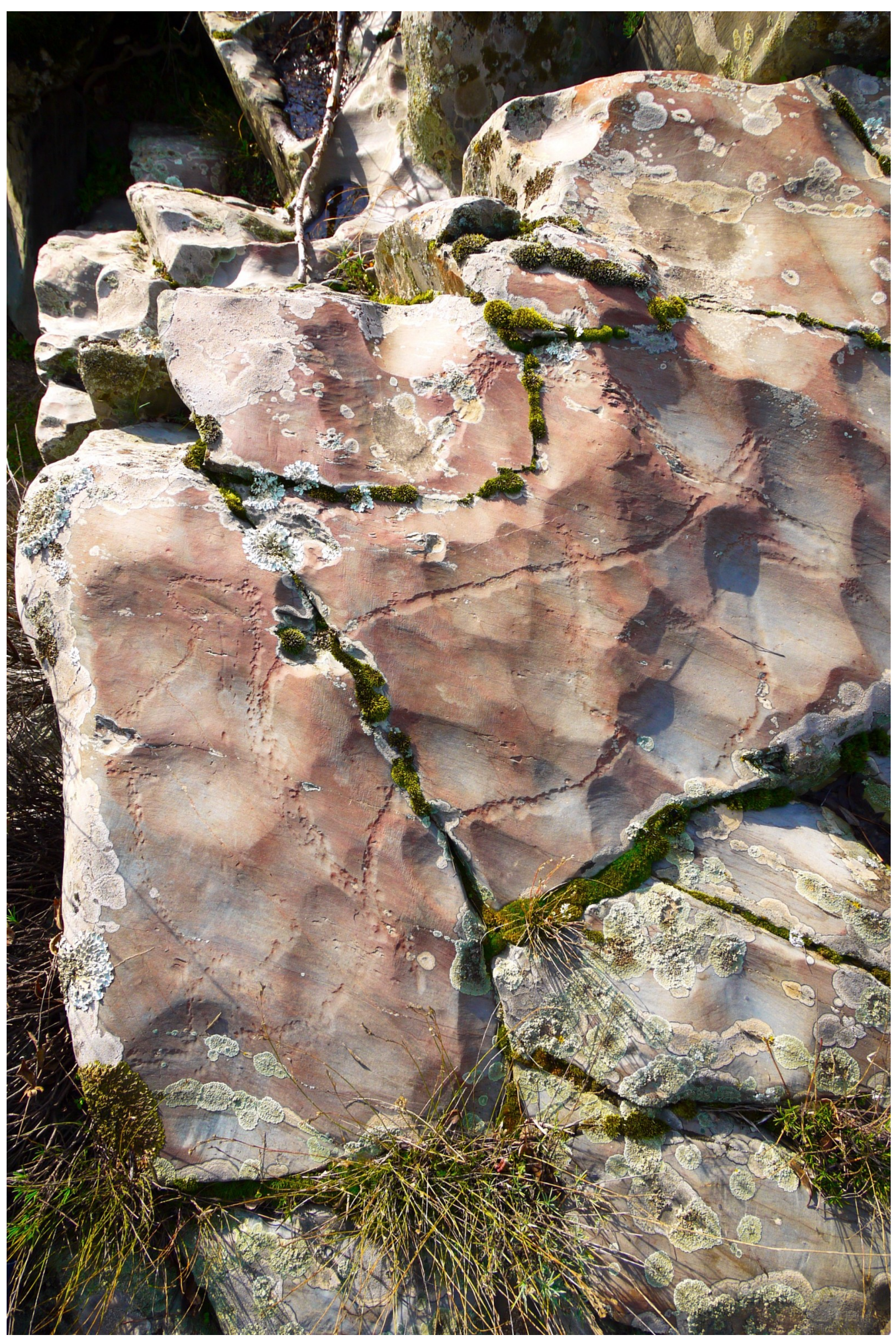

Fig. 14. Panel 67. Équido y reno. Fotografía (C) Carlos Vázquez Marcos y Javier Angulo Cuesta.

Fig. 14. Panel 67. Equid and reindeer. Photograph $(\mathcal{C}$ Carlos Vázquez Marcos and Javier Angulo Cuesta. 


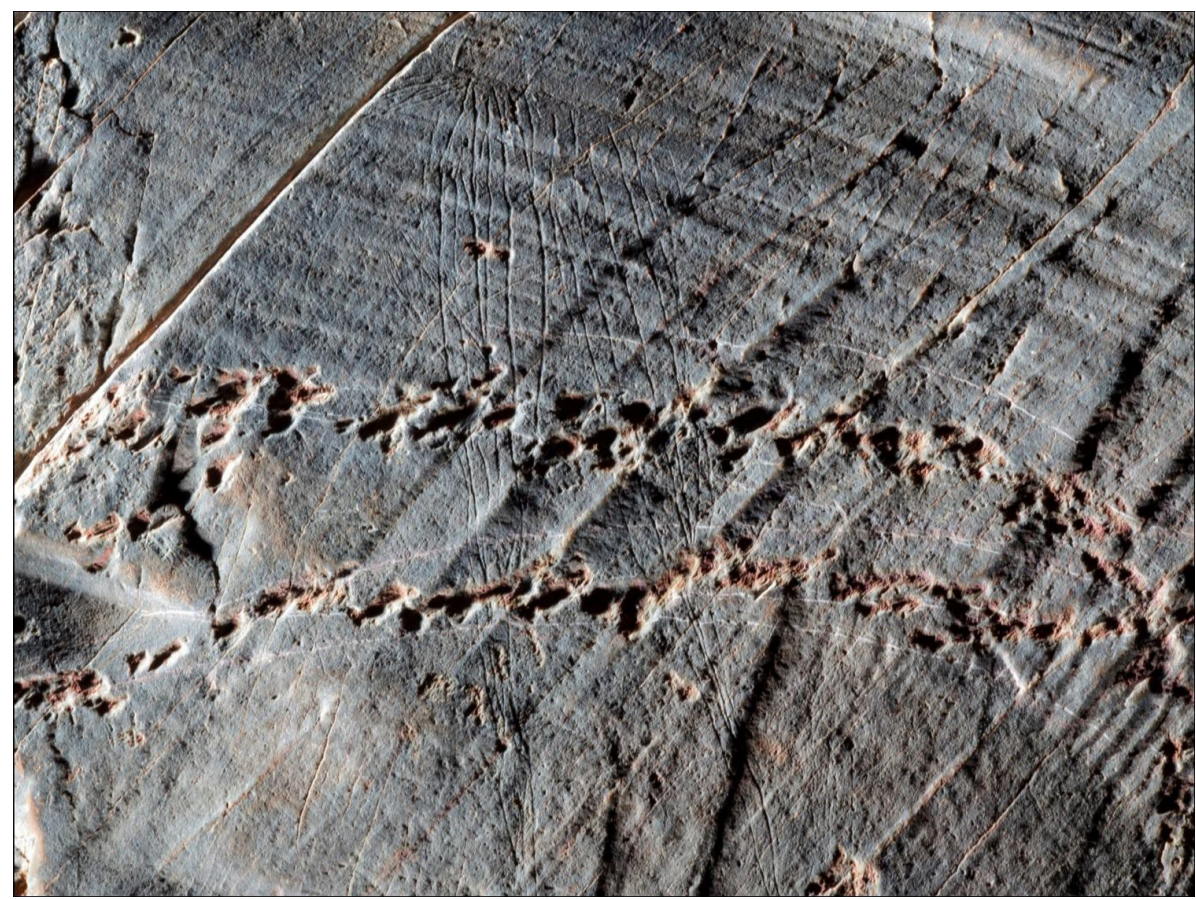

Fig. 15. Panel 48. Extremidades de un zoomorfo inciso que está superpuesto al équido creado por piqueteado. Fotografía (C) Carlos Vázquez Marcos.

Fig. 15. Panel 48. Extremities of a zoomorphic figure made by incision which is superimposed on the equid engraving is created by pecking. . Photograph (C) Carlos Vázquez Marcos.

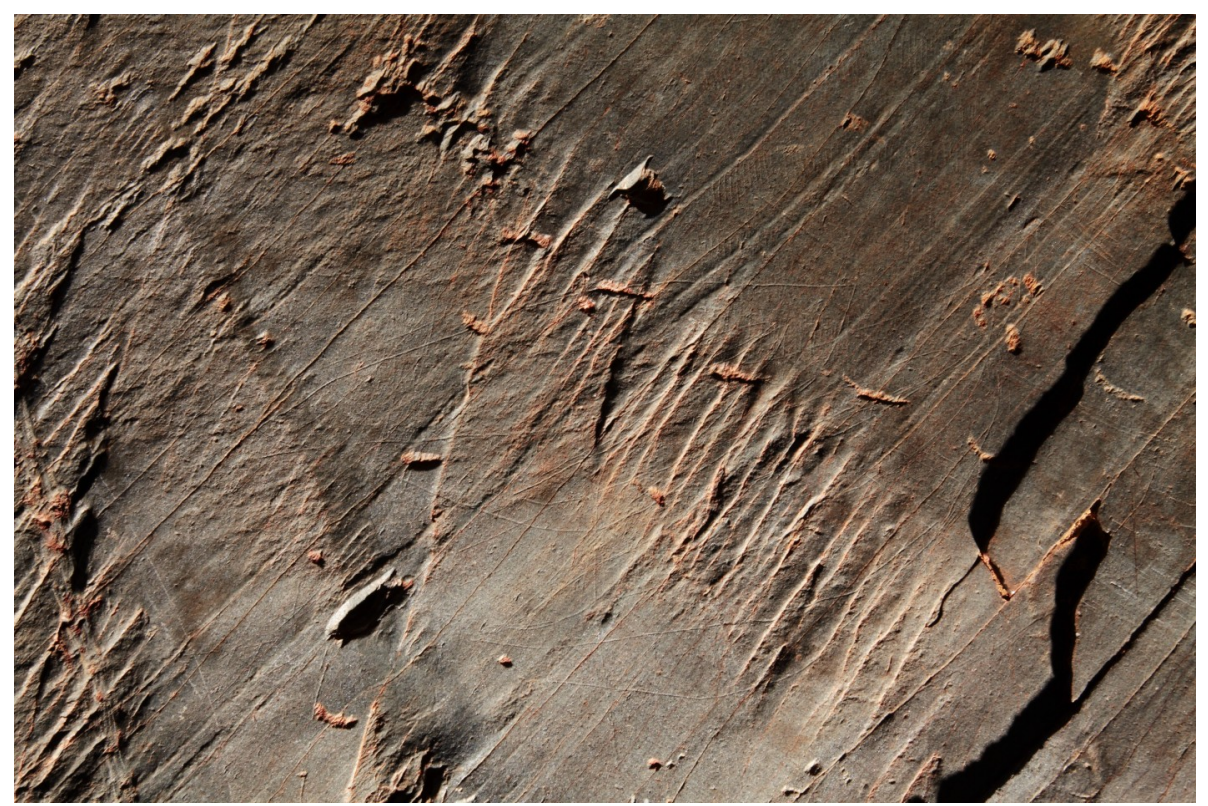

Fig. 16. Panel 48. Peces y signos. Fotografía (C) Mário Reis y Carlos Vázquez Marcos.

Fig. 16. Panel 48. Fish and signs. Photograph (C) Mário Reis and Carlos Vázquez Marcos.

Un momento que emerge de la civilización Magdaleniense, sin ruptura ni decadencia gráfica, evidenciando un intencionado cambio conceptual que continua hasta el horizonte gráfico naturalista del Epipaleolítico inicial (GARCÊS 2017), o microlaminar, no sin cambios en su técnica, dimensiones, especies o implantación.

Esta última fase gráfica, si exceptuamos el vigoroso arte agro-pastoril y popular de los siglos XIX y XX localizado en sus inmediaciones, por el autor de este texto y Mário Reis, se desarrolló entre la segunda mitad del Tardiglaciar y el Holoceno temprano, desde el Interestadial GI 1 (Greenland Interstadial 1) al OIS 1, previo paso por la fase glacial GS 1 (Greenland Stadial 1), entre los $\sim 12,000$ y los $\sim 9,000$ años BP $(14,000-10,500$ cal 
BP) (JÖRIS \& ÁlVAREZ FERNÁNDEZ 2002: 314 315; RASMUSSEN et al. 2014), corroborado tanto por las dataciones numéricas indirectas y estatigráficas de los materiales de los sitios portugueses del valle del Côa de Fariseu, unidad estatigráfica 4 de la roca 1, de Quinta da Barca Sul, unidad estatigráfica 3, o Cardina I, unidad estatigráfica 4, como por los análisis de las 89 piezas sobre soportes líticos muebles del sitio de Fariseu, unidad estatigráfica 4 de la roca 1 (AUBRY \& SAMPAIO 2008: 222; AUBRY et al. 2017: 405-406; SANTOS et al. 2018), o por las placas y cantos pizarrosos del abrigo de Estebanvela (Ayllón, Segovia) (GARCíA DiEz $\&$ CACHO 2015), en sus dos primeros niveles, además de por las dataciones directas ofrecidas tanto por las 5 muestras, entre $11,470 \pm 110 \mathrm{y}$ $10,950 \pm 100$ años BP, de varias representaciones figurativas, zoomorfas y antropomorfas, y signos de la sala de las pinturas de Cueva Palomera (Ojo Guareña, Burgos) (CORCHÓN et al. 1996: 42-46) o el promedio ponderado ofrecido por las dataciones de Cova Eirós (Triacastela, Lugo) $(9,700$ y 8,600 cal BP) (STEELMAN et al. 2017: 160-161).

Quisiera incidir en que este ciclo también ha sido inventariado en otros enclaves al aire libre peninsulares como en El Cerro de san Isidro o Las Canteras (Segovia) (RIPOLL \& Municio 1999: 8889 ; 107-109; 129-130), en el Tua (TEIXEIRA \& SANCHES 2017: 39), en el Guadiana (COLlADO 2006, 2008; BAPTISTA \& SANTOS 2013), en la roca 23 de Quinta da Barca, la roca 14 de Canada do Inferno, las 52, 103 o 149 de Foz do Côa, la roca 1 de Vermelhosa, la roca 16 de José Esteves, la 7 de Vale de João Esquerdo, por citar algunos de los cientos de buenos ejemplos conocidos del arte del Côa (BUENO et al. 2008; BAPTISTA 2009, 2012: 308, 320-321; RIVERO 2010: 91; REIS 2014: 36-38) o en ambientes abrigados del mediterráneo peninsular más septentrional como el Abric de la Belladona (Ares del Maestrat, Catellón), Cova del Bovalar (Culla, Castellón), Abric del Cingle del Barranc de l'Espigolar (La Serratella, Castellón), Abric del Barranc de la Marfullada II (Ares del Maestrat, Benassal Catellón), Abrigo d' en Meliá (La Serra d'en Galceran, Castellón), Mas de Serramporta (Culla, Castellón), Mas de la Vall (Ares del Maestrat, Catellón), Llaberia P-IV (Capçanes, Tarragona) o Cañada de Marco (Alcaide, Teruel) (MARTÍNEZ VAlle et al. 2003; RUIZ LÓPEZ \& ROYO LASARTE 2016; ROMÁN \& DOMINGO 2017) e incluso en otros territorios extra-peninsulares sobre soportes muebles (GARCÍA DIEZ \& CACHO 2015: 31; Di MAIDA et al. 2018) o parietales (SANTOS et al. 2018: 58-66).

En Siega Verde la especie zoomorfa mayoritariamente grabada en las fases anteriores, los équidos, pierde esa posición de privilegio numérico al igual que en el valle del Côa (REIS 2014; SANTOS 2015: 23-24), Domingo García o Arroyo de las Almas. Ahora serán los ciervos y las cabras, junto a los peces o pisciformes, que aparecen por primera vez representados, panel 48 de Siega Verde (BUENO et al. 2008: 267) (Fig. 16), los dominantes. Con respecto al bovino más representado, el uro, recalcar su enigmática ausencia en Siega Verde o su drástica reducción en los restantes conjuntos de la cuenca del Duero. Además, al igual que en el grafismo cronoculturalmente precedente, la convivencia entre representaciones zoomorfas y signos, haces de líneas, retículas, zig-zags o signos en "alambre de espino" (BUENO et al. 2008: 265-269), se muestra como un hecho recurrente (Fig. 16).

En cuanto a la técnica de grabado utilizada en esta ultima fase, destacar el dominio exclusivo de la incisión, en varias de sus posibles modalidades, preferentemente simple, en trazos únicos y repetidos, así como la homogeneidad morfoestilística en las representaciones zoomorfas con un estilo subnaturalista, tendencia geometrizante y esquemática, cuerpos fusiformes, abundantes rellenados internos realizados mediante las modalidades incisas señaladas, una deliberada falta de atención a las partes capitales o detalles internos con cuellos estrechos y proyectados hacia adelante, cabezas pequeñas con tendencia triangular y extremidades, no siempre cortas, grabadas en perspectivas diferentes, que asiduamente finalizan en líneas convergentes realizadas por haces de líneas, además de tener reducidas dimensiones: ratificando que la información visual que intentan suministrar es otra a la de las UGs de momentos cronoculturales precedentes.

Figuras zoomorfas y signos que han sido localizados tanto superpuestos a las manifestaciones anteriores (panel 48); argumento utilizado en la autentificación de las primeras (ALCOLEA \& BALBín 2006: 305-322) (Fig. 15), como junto a ellas, panel 8 , e incluso en paneles donde no se tiene constancia de las primeras. Una fase de tránsito y mantenimiento de previas cosmovisiones y técnicas paleolíticas que permite apuntalar una visión sobre la ocupación humana de la Península Ibérica y del arte de los últimos grupos de tradición paleolítica, que debería ser indefectible en el estudio de sus relaciones sociales y culturales y de las redes de intercambio locales, regionales y suprarregionales en momentos de cambio (SAUVET 2017) y donde las respuestas a los diferentes eventos climáticos registrados, preferentemente fríos, no tienen por que ser idénticas en territorios contiguos (TOMASSO et al. 2018).

Estas balizas cronológicas propuestas para la última fase del sitio, al igual que las precedentes, no caen en la "doble asunción" a la que en ocasiones nos ha llevado la comparativa estilística en ausencia de dataciones numéricas (PETZINGER \& NowELL 2011: 1170), al estar sólidamente sustentado por dataciones numéricas directas e indirectas $\mathrm{y}$ análisis formales, y no solo en criterios estilísticos, que se muestran como una esencial y nada desdeñable variable para entender las sociedades 
prehistóricas que llevaron a cabo dichas manifestaciones gráficas tanto en Siega Verde como en otros enclaves, independientemente del soporte (RIVERO \& SAUVET 2014: 77; RIVERO 2016: 97-98).

\section{CONSIDERACIONES FINALES}

A través de este bosquejo he intentado acercarme, y acercar al lector, al conocimiento actualizado sobre Siega Verde e intentar desplazar, aunque sea un solo palmo, la barrera de lo incognoscible sobre este complejo y diacrónico arte parietal Paleolítico tan íntimamente ligado al arte Paleolítico del río Côa y Duero, cuando este penetra en Portugal, al igual que al registrado, independientemente de su soporte, en el interior de la Meseta y en los principales sitios cavernarios o abrigados de otras "regiones" gráficas del territorio peninsular (AlCOlEA \& BALBÍN 2006; BUENO et al. 2008; RIVERO 2010: 94; VÁZQUEZ MARCOS 2017; GARATE 2018: 190; SANTOS 2017).

Parece coherente afirmar, a tenor de lo escrito y argumentado más arriba, que la propagación de estas imágenes paleolíticas, y su movilidad, debería ser percibida como un esencial vector de unificación de sistemas de representación al igual que parte de una misma tradición gráfica donde cada sitio conserva su propia originalidad. En Siega Verde, sin embargo, la existencia de varios símbolos figurativos zoomorfos y signos endógenos, nos lleva a cuestionar la existencia de este sistema aunque el soporte y el ambiente sea el mismo. Sin ser capaz de atestiguar si se trata de un fracaso de difusión entre lugares o territorios cercanos, los exiguos datos arqueológicos y paleoambientales conocidos, nos obligan a repensar nuestra forma de percibir los intercambios y de entender las sociedades prehistóricas en este espacio. Tanto las cordilleras montañosas como los cursos fluviales que rodean Siega Verde, aunque pudieron condicionar las actividades que desarrollaron sus individuos, entre Pleistoceno Superior Final y el Holoceno Temprano, no supusieron, al menos en determinados momentos climáticos, obstáculos o primeras "fronteras" que no pudieran ser traspasadas. Una afirmación sustentada por los firmes estudios y conclusiones obtenidas sobre el tránsito de materias primas en tiempos pre-magdalenienses (AUBRY et al. 2012).

Quizá, los nuevos proyectos a desarrollar en este amplio territorio, simbólico y físico, deberían ser elaborados no solo a través de la movilidad sino desde la sedentarización de estos grupos prehistóricos (VÁZquez Marcos \& ANGUlo Cuesta p.p.), como se ha demostrado en otros territorios cercanos (AUBRY et al. 2015: 24).

Siega Verde, estaría lejos por tanto; como apuntan sus grafías Paleolíticas, de constituir un "apéndice" del arte del Côa, ya que su ventajosa ubicación como lugar de tránsito y paso obligado entre regiones naturales que se comunican en un territorio abierto respecto a otras áreas geográficas colindantes más cerradas, ejercería un esencial papel de catalizador de los flujos de población, materiales e ideas, en ambas direcciones.

\section{AGRADECIMIENTOS}

Este trabajo no se habría podido realizar sin la colaboración de muchas personas. Agradecer, en primer lugar, a quienes que me han cedido su material fotográfico, y mapa que acompaña el texto (Manuel Santonja Gómez, Pedro Guimarães, Mário Reis y Javier Angulo Cuesta). Asimismo, quisiera reconocer los valiosos comentarios realizados, por parte de los dos revisores de la revista Estudos do Quaternario, que han fortalecido mi reflexión sobre el sitio arqueológico de Siega Verde y su arte Paleolítico, y que no recibió concesión alguna de fondos provenientes de los sectores público, comercial o no lucrativo para su realización.

\section{BIBLIOGRAFÍA}

Alcaraz-Castaño, M.; Alcolea, J.J.; Balbín, R. De.; M. GARCÍA, M.; YraVEdRA, J. \& BAENA, J. 2013. Los orígenes del Solutrense y la ocupación pleniglaciar del interior de la Península Ibérica: Implicaciones del nivel 3 de Peña Capón. Trabajos de Prehistoria, 70: $28-53$.

Alcolea, J. J. \& Balbín, R. de. 2003. El Arte Rupestre Paleolítico del interior peninsular: Nuevos elementos para el estudio de su variabilidad regional. En: R. De Balbín \& P. Bueno (eds.), El Arte Prehistórico desde los inícios del siglo XXI, Ribadesella, Asociación Cultural Amigos de Ribadesella/Primer Symposium Internacional de Arte Prehistórico de Ribadesella: 223-253.

AlcoleA, J. J. \& BAlbÍn, R. DE. 2006. Arte Paleolitico al Aire Libre. El yacimiento rupestre de Siega Verde, Salamanca. Arqueología en Castilla y León, Memorias 16, Junta de Castilla y León.

Alcolea, J. J. \& BALbín, R. DE. 2008. El Yacimiento Rupestre de Siega Verde, Salamanca. Una visión de síntesis. En: R. De BALBín (ed.), Arte prehistórico al aire libre en el Sur de Europa, Junta de Castilla y León: 57-87.

Alonso Gavilán, G. \& Cantano Martín, M. 1987. La Formación Areniscas de Ciudad Rodrigo: Ejemplo de sedimentación controlada por paleorrelieves (Eoceno, fosa de Ciudad Rodrigo). Studia Geologica Salmanticensia, 24: 247-258.

Angulo, J. \& Moreno, E. 2010. Conoce Los Casares Madrid.

AUBRY, T. 2002. Le contexte archéologique de l'art paléolithique à l'air libre de la vallée du Côa. In: D. SACCHI (ed.), L'art paléolithique à l'air libre. Le paysage modifié par l'image, Tautavel - Campôme, 7-9 octobre 1999, Tautavel: 25-38.

AUBRY, T. 2006. Vallée du Côa. Un art préhistorique unique. Archéologia, 436: 62-71.

AuBry, T. 2009. 200 séculos da história do Vale do Côa: Incursões na vida quotidiana dos caçadores artistas do Paleolítico. Trabalhos de Arqueologia 52, Lisboa, IGESPAR 
Aubry, T. 2015. Peuplement de l'intérieur de la Péninsule Ibérique pendant le Paléolithique supérieur: où en est-on?, ARPI, 03 Extra, Homenaje a Rodrigo de Balbín Behrmann: 20-31.

Aubry, T. \& SAMPAIO, J. D. 2008. Chronologie et contexte archéologique des gravures paléolithiques de plein air de la Vallée du Côa (Portugal). En: R. DE BALBín (ed.), Arte prehistórico al aire libre en el Sur de Europa, Junta de Castilla y León: 211-223.

Aubry, T.; Luís, L.; Mangado, X. \& Matias, H. 2012. We will be known by the tracks we leave behind: Exotic lithic raw materials, mobility and social networking among the Côa Valley foragers (Portugal). Journal of Anthropological Archaeology, 31, 4: 528-550.

Aubry, T.; SANTos, A. T. \& Luís, L. 2014. Stratigraphies du panneau 1 de Fariseu: analyse structurelle d'un système graphique paléolithique à l'air libre de la vallée du Côa (Portugal). In: P. PAILlET (ed.), Les arts de la Préhistoire: micro- analyses, mises en contextes et conservation. Actes du colloque, Microanalyses et datations de l'art préhistorique dans son contexte archéologique, MADAPCA - Paris, 16-18 novembre 2011, Les Eyzies: SAMRA, Paleo, numéro spécial: 259- 270.

Aubry, T.; Barbosa, A. F.; Gameiro, C.; Luís, L., MAtias, H.; SAntos, A. T. \& Silvestre, M. 2015. De regresso à Cardina, 13 anos depois: resultados preliminares dos trabalhos arqueológicos de 2014 no Vale do Côa. Revista Portuguesa de Arqueologia, volume 18: 5-26.

Aubry, T.; Gameiro, C.; Santos, A. \& Luís, L. 2017. Existe Azilense em Portugal? Novos dados sobre o Tardiglaciar e o Pré-boreal no Vale do Côa. In: J. ARNAUd \& A. MARTINS (Eds.), Arqueologia em Portugal: 2017 - Estado da Questão. Associação dos Arqueólogos Portugueses. Lisboa: 403-418.

BAHN, P. 2015. Open-air Ice Age art: the history and reluctant acceptance of an unexpected phenomenon. In: P. Bueno \& P. BAHN (eds.), Prehistoric Art as Prehistoric Culture Studies in Honour of Professor Rodrigo de Balbin-Behrmann. Archaeopress $\mathrm{Ar}-$ chaeology, Oxford: 79-92.

BALBÍN, R. DE. 2008. El Arte Rupestre Paleolítico al aire libre en la Península Ibérica. En: R. DE BALBÍN (ed.), Arte prehistórico al aire libre en el Sur de Europa, Junta de Castilla y León: 19-56.

Balbín, R. DE. \& Alcolea, J. J. 1994. Arte paleolítico de la Meseta española. Complutum, 5: 97-138.

Balbín, R. DE. \& Alcolea, J. J. 2001. Siega Verde et l'art paléolithique de plein air: quelques précisions sur son contenu sa chronologie et sa signification. In: J. ZILHÂO; T. AUBRY \& A.M.F. CARVALHO (eds.), Les premiers hommes modernes de la Péninsule Ibérique. Actes du Colloque de la Commission VIII del UISPP, Lisboa, Instituto Português de Arqueologia, Trabalhos de Arqueologia, 17: 205-236.

Balbín, R. DE. \& AlcoleA, J. J. 2006. Siega Verde y el Arte Paleolítico al aire libre del interior peninsular. En: G. DElibes DE CASTRO \& F. DiEz MARTIN (eds.), El Paleolítico Superior en la Meseta Española, Valladolid, Studia Archaeologica, 94: 41-74.

Balbín, R. DE. \& Alcolea, J. J. 2014. Siega Verde. En: R. SAlA (ed.), Los Cazadores-Recolectores del Pleistoceno y del Holoceno en Iberia y el Estrecho de Gibraltar: Estado Actual del Conocimiento del Registro Arqueológico, Burgos: 601-607.
BAlbÍn, R. DE. \& AlcoleA, J. J. 2017. Lo cotidiano y lo religioso en el mundo gráfico paleolítico, Veleia, 34: 13-27.

Balbín, R. DE.; Alcolea, J.J. ; SAntonja, M. \& PÉRez, R. 1991. Siega Verde (Salamanca). Yacimiento artístico paleolítico al aire libre. En: M. SANTONJA (ed.), Del Paleolitico a la Historia, Salamanca, Museo de Salamanca: 33-48.

BAPTISTA, A. M. 1983. O complexo de gravuras rupestres do Vale da Casa (Vila Nova de Foz Côa), Arqueologia 8: 57-69.

BAptista, A. M. 1999. No tempo sem tempo: A arte dos caçadores paleoliticos do Vale do Côa. Com uma perspectiva dos ciclos rupestres pós-glaciares. Vila Nova de Foz Côa, Parque Arqueológico do Vale do Côa/Centro Nacional de Arte Rupestre.

BAPTISTA, A. M. 2009. O paradigma perdido. O Vale do Côa e a Arte Paleolitica de Ar Livre em Portugal. Lisboa, Afrontamento.

Baptista, A.M. 2012. El Arte Paleolítico en Portugal. En: I. ESCOBAR \& B. RODRÍGUEZ (eds.), Arte sin artistas. una mirada al Paleolítico. Alcalá de Henares, Madrid, Museo Arqueológico Regional: 305-338.

BAPtista, A. M. \& REIS, M. 2008. Prospecção da Arte rupestre no Vale do Côa e Alto Douro Português: ponto da situação em Julho de 2006. En: R. DE BALBÍn (ed.), Arte prehistórico al aire libre en el sur de Europa, Junta de Castilla y León: 145-192.

BAPTISTA, A. M. \& REIS, M. 2011. A rocha gravada de Redor do Porco. Um novo sítio com arte paleolítica de ar livre no rio Águeda (Escalhão, Figueira de Castelo Rodrigo). Côavisão, 13: 15-20.

BAPtistA, A. M. \& SAntos, M. 2013. A arte rupestre do Guadiana português na área de influência do Alqueva. Memórias d'Odiana, 1.

BAPTISTA, A.M. \& SANTOS, A.T. 2013. A arte rupestre do Guadiana portugues na area de influencia do Alqueva. Memorias d'Odiana.

Baptista, A. M.; SAntos, A. T. \& CorreiA, D. 2008. O santuário arcaico do Vale do Côa: novas pistas para a compreensão da estruturação do bestiário gravettense e/ou gravetto-solutrense. En: R. DE BALBÍn (ed.), Arte prehistórico al aire libre en el sur de Europa, Junta de Castilla y León: 89-144.

Bicho, N. \& CASCALHEIRA, J. 2018. Global perspectives on the impact of drastic environmental changes in hunter-gatherer technologies. Journal of Quaternary Science, 33 (3): 255-260.

BuENO, P. \& BALBÍN R. DE. 2016. De cazadores a productores. Transiciones y tradiciones. En: Del neolitic a l'edat del bronze en el Mediterrani occidental, Estudis en homenatge a Bernat Martí Oliver, TV SIP 119: 465-480.

Bueno, P.; Balbín, R. DE. \& Alcolea, J. J. 2008. Estilo V en el ámbito del Duero: Cazadores finiglaciares en Siega Verde (Salamanca). En: R. DE BALbín (ed.), Arte prehistórico al aire libre en el Sur de Europa, Junta de Castilla y León: 259-286.

Burón, M. \& Del VAl Recio, J. 2013. La zona arqueológica de Siega Verde. En: M. SALINAS DE FríAs (coord.), Interpretar la Frontera: Jornadas de Patrimonio, Turismo y Desarrollo Local, Salamanca: 101-113.

Cacho, C.; Martos, J.A.; Jordá, J.; Yravedra, J.; Ave- 
ZUEla, B.; VAldivia, J. \& Martín, I. 2010. El Paleolítico superior en el interior de la Península Ibérica. Revisión crítica y perspectivas de futuro. En: X. Mangado (ed.), El Paleolítico Superior peninsular. Novedades del siglo XXI. Barcelona: 115-136.

Clottes, J. 2010. Cave art. Phaidon Press.

Collado, H. 2008. Arte rupestre prehistórico en Extremadura: 1997-2006. En: R. DE BALBín (ed.), Arte prehistórico al aire libre en el Sur de Europa, Junta de Castilla y León: 287-322.

Corchón, M.S.; Valladas, H.; BÉCARes, J.; Arnold, M.; TiSnerat, N. \& CACHIER, H. 1996. Datación de las pinturas y revisión del arte paleolítico de Cueva Palomera (Ojo Guareña, Burgos, España), Zephyrus, 49: 37-60.

CORCHÓN, M.S. 2006. Reflexiones sobre el Arte paleolítico interior: la Meseta Norte española y sus relaciones con Portugal. Zephyrus, 59:111-134.

Corchón, M. S.; Hernando, C.; Rivero, O.; Garate, D. \& Ortega. P. 2012 La cueva de La Griega (Pedraza, Segovia, España) en la encrucijada ibérica: nuevos análisis del arte parietal paleolítico a través del Análisis Factorial de Correspondencias. En: S. Ripoll López ; B. Avezuela ARISTU; J. JORDÁ PARDO \& F. MuÑoz IBÁÑEZ (eds.). De punta a punta. El Solutrense en los albores del siglo XXI. Actas del Congreso Internacional "El Solutrense - Centenario de las excavaciones en La Cueva de Ambrosio (Velez-Blanco, Almeria, Espana, del 25 al 28 de junio de 2012), Serie I. Nueva época. Prehistoria y Arqueología, 5: 527-542.

Di Maida, G.; García-Diez, M.; Pastoors, A. \& TerberGER, T. 2018. Palaeolithic art at Grotta di Cala dei Genovesi, Sicily: A new chronology for mobiliary and parietal depictions. Antiquity, 92 (361): 38-55.

Escudero, C. 2011. Conservación del paisaje de Siega Verde. En: J. J. FERNÁNDEZ-MORENO \& M. BURÓN (eds.), Siega Verde. Arte Paleolítico al Aire Libre, Junta de Castilla y León: 65-68.

FERNANDES, A.P.B. 2012. Natural processes in the degradation of open-air rock-art sites: an urgency intervention scale to inform conservation. Bournemouth: Bournemouth University, Tese de doutoramento.

FERnANDES, A.P.B.; ReIS, M.; Escudero RamíReZ, C. \& VÁZQUEZ MARCOS, C. 2017. Integration of natural stone features and conservation of the Upper Palaeolithic Côa Valley and Siega Verde open-air rockart. Time and Mind: 1-27.

FERnANDES, A.P.B. \& VÁzQuez Marcos, C. 2018. Arte Paleolítico en los valles meridionales del Duero: Ríos Águeda y Côa (Castilla y León -Esp- y Territorio Norte -Pt-). En: El arte Paleolitico del Suroeste de Europa en la Lista del Patrimonio Mundial: 28-31.

Fernández Moreno, J.J. \& BAPTISTA, A.M. 2010. Siega Verde. Extensión del Valle del Côa: arte rupestre paleolitico al aire libre en la cuenca del Duero. Junta de Castilla y León.

Fernández Moreno, J.J. \& Burón, M. 2011. Siega Verde. Arte Paleolítico al Aire Libre, Junta de Castilla y León.

Figueiredo, S.; Xavier, P.; Silva, A.; Neves, D. \& DomínGUEZ, I. 2014. The Holocene transition and postpalaeolithic rock art from the Sabor Valley (Trás-Os -Montes, Portugal). En: M.A.MedINA-AlCAIDE ;
A.J. Romero Alonso ; R.M. RUIZ-MÁrQUEZ \& J L. SANCHIDRIÁN TORTI (eds.), Sobre rocas y huesos: las sociedades prehistóricas y sus manifestaciones plásticas, Imprenta Luque: 193-203.

GARCÊS, S. 2017. Cervídeos: Símbolos e Sociedade nos primórdios da agricultura no Vale do Tejo. Universidade de Trás-os-Montes e Alto Douro, Tese de Doutoramento, Vila Real.

GARCÊS, S. \& NASH, G. 2017. The relevance of watery soundscapes in a ritual context. Time and Mind, 10 , 1: 69-80.

Garate, D.; Rios, J.; PÉrez, R.; RoJAs, R. \& SANTONJA, M. 2016. Arte rupestre paleolítico al aire libre en el paraje de La Salud, Valle del Tormes, Salamanca, Zephyrus, 77: 15-29.

Garate, D. 2018. New Insights into the Study of Paleolithic Rock Art: Dismantling the "Basque Country Void". Journal of Anthropological Research, 74, no. 2: 168 $-200$

García Diez, M. \& CACHO, C. 2015. Beyond LeroiGourhan's Style IV: portable art at La Peña de Estebanvela Rock-shelter (Segovia, Spain). Journal of Anthropology and Archaeology, Vol 3, no. 1: 23-36.

GuY, E. 1993. Enquête stylistique sur l'expression figurative épipaléolithique en France de la forme au concept. Paleo, 5: 333-373.

HERNANDO, C. 2014. La sociedad a través del arte: Las tradiciones gráficas premagdalenienses en la región cantábrica, Tesis de Doctorado, Universidad de Salamanca.

Hoffmann, D. L.; Standish, C. D.; García-Diez, M. Pettitt, P. B. ;Milton, J. A.; Zilhão, J.; Alcolea -GonzÁlez, J.J.; Cantalejo-Duarte, P.; CollaDO, H. ; DE BALBÍN, R.; LORBLANCHET, M. ; RAmos-Muñoz, J. ; Weniger, G.-CH. \& PIKE, A. W G. 2018. U-Th dating of carbonate crusts reveals Neandertal origin of Iberian cave art. Science, Vol. 359, Issue 6378: 912-915.

Huyge, D. ; Vandenberghe, D.; De Dapper, M.; Mees, F.; Claes, W. \& Darnell, J. 2011. First evidence of Pleistocene rock art in North Africa: securing the age of the Qurta petroglyphs (Egypt) through OSL dating. Antiquity, 85: 1184-1193.

JÖRIS, O. \& ÁlVAREZ FERnÁNDEZ, E. 2002. Algunas precisiones sobre la terminología empleada en la segunda parte del Tardiglaciar en Europa Central y el problema de su aplicación en el sw de Europa. Zephyrvs, 55: 313-322.

JordÁ PARdo, J.; PASTOR MuÑoz, F. \& RiPOll LÓPEZ, S. 1999. Arte rupestre paleolítico y postpaleolítico a aire libre en los Montes de Toledo occidentales (Toledo, Castilla-La Mancha): noticia preliminar, Zephyrus, 52: 281-296.

Jorge, S. O.; Jorge, V.O.; Almeida, C. A. F.; SANChes, M J. \& SoEIRO, M. T. 1981. Gravuras rupestres de Mazouco, Arqueologia, 3, Porto: 3-12.

Leroi Gourhan, A. 1971. Préhistoire de l'art occidental. Éditions d'Art Lucien Mazenod. Paris.

Luís, L. 2008. A Arte e os Artistas do Vale do Côa. Vila Nova de Foz Côa: Parque Arqueológico do Vale do Côa/ Associação de Municípios do Vale do Côa.

Luís, L. 2012. Desenhos animados! Uma gramática do movimento para a arte paleolítica do vale do Côa. In M. D. J. SAnches (ed.), $1^{a}$ Mesa Redonda. Artes 
Rupestres da Pré-história e da Proto-história: paradigmas e metodologias de registo, Lisboa, DGPC, Trabalhos de Arqueologia, 54: 69-80.

Mateos Cachorro, A. 2010. Historias de fósiles. Humanos por descubrir. En: A. Perote Alejandre \& A MATEOS CACHORRO (Coords.), 150 años después de Darwin: jevolución, futuro o crisis?. Lecciones sobre evolución humana. INSTITUTO TOMÁS PASCUAL SANZ-CENIEH, Madrid: 33-41.

Martínez, J. 2008. Arte Paleolítico al aire libre en el sur de la Península Ibérica: Andalucía. En: R. DE BALBín (ed.), Arte prehistórico al aire libre en el sur de Europa. Junta de Castilla y León: 237-258.

Martínez Valle, R.; Calatayud, P. G. \& Villaverde, V. 2003. Las figuras grabadas de estilo paleolítico del Abric d'en Meliá (Castelló): reflexiones en torno a la caracterización final del arte paleolítico de la España mediterránea. En: R. DE BALBÍN \& P. BUENO (eds.), El Arte Prehistórico desde los inícios del siglo XXI, Ribadesella, Asociación Cultural Amigos de Ribadesella/Primer Symposium Internacional de Arte Prehistórico de Ribadesella: 279-290.

PÉREZ, P. P. 2011. La geología del yacimiento de Siega Verde. En: J. J. FERnÁNDEZ MORENO \& M. BuRÓN (Eds.), Siega Verde. Arte Paleolítico al Aire Libre. Junta de Castilla y León: 20-25.

Petzinger, G. V. \& Nowell, A. 2011. A question of style: reconsidering the stylistic approach to dating Palaeolithic parietal art in France. Antiquity, 85, 330: 1165-1183.

Pigeaud, R. 2005. Los caballos en la Cova del Parpalló (Gandía, Valencia). SAGVNTVM, 37: 9-16.

Rasmussen, S.O.; Bigler, M.; Blockley, S.P.; Blunier, T.; Buchardt, S.L.; Clausen, H.B.; CVijanovic, I.; DAHL-Jensen, D.; JOHNSEN, S.J.; FISCHER, H.; GKINIS, V.; GUILleVIC, M.; HoEH, V.Z.; LOWE, J.J.; PEDro, J.B.; PopP, T.; SeIERSTAD, I.K.; StefFEnSEN, J.P.; SVensson, A.M.; VAllelonga, P.; VInTHeR, B.; WALKER, M.J.C.; WhEATLEy, J.J. \& WinSTRUP, M. 2014. A stratigraphic framework for abrupt climatic changes during the Last Glacial pe-riod based on three synchronized Greenland ice-core records: refining and extending the INTIMATE event stratigraphy. Quaternary science reviews, 106: 14-28

REIS, M., 2012. Mil rochas e tal...!: Inventário dos sítios da arte rupestre do vale do Côa. Porto, Portvgalia, 33: $5-72$.

REIS, M., 2013. Mil rochas e tal...!: Inventário dos sítios da arte rupestre do vale do Côa $\left(2^{\circ}\right.$ parte). Porto, Portvgalia, 34: 5-68.

REIS, M., 2014. Mil rochas e tal....!: Inventário dos sítios da arte rupestre do vale do Côa (conclusão). Porto, Portvgalia, 35: 17-59.

Reis, M. \& VÁzQuez Marcos, C. 2015. Arte rupestre en la frontera hispano-portuguesa: cuenca del río Águeda. ARPI, 03 Extra, Homenaje a Rodrigo de Balbín Behrmann: 32-43.

Ripoll, S. \& Municio, L. 1999. Domingo García. Arte Rupestre Paleolítico al aire libre en la meseta castellana. Arqueología en Castilla y León, Memorias 8, Junta de Castilla y León.

RIVERO, O. 2010. Las manifestaciones artísticas al aire libre al sur del río Duero: los yacimientos de Foz Côa y Siega Verde en el contexto del arte paleolítico peninsular. En: N. CUBAS MARTín; D. HIDALGO \&
M. SALINAS DE FRÍAS (eds.), Arqueología, patrimonio, prehistoria e historia antigua de los pueblos "sin pasado" ecos de la lusitania en Arribes del Duero, Ediciones Universidad de Salamanca: 83-96.

RIVERO, O. 2016. Master and apprentice: Evidence for learning in palaeolithic portable art. Journal of Archaeological Science, Volume, 75: 89-100.

Rivero, O. \& SAuvet, G. 2014. Defining Magdalenian cultural groups in Franco-Cantabria by the formal analysis of portable artworks, Antiquity, 88, 339: 64-80.

RomÁn, D. \& Domingo, I. 2017. El final del Paleolítico superior en Castellón: un territorio clave para la comprensión del final del Pleistoceno en el Mediterráneo ibérico. Pyrenae, 48, 1: 47-70.

Ruiz LóPez, J. F. \& Royo LASARTe, J. 2016. Guía Cañada de Marco. Zaragoza, Prames y Ayuntamiento de Alcaine (Teruel).

SACCHI, D. 2008. Le rocher gravé de Fornols vingt trois ans après sa découverte. In: R. DE BALBÍn (ed.), Arte prehistórico al aire libre en el Sur de Europa, Junta de Castilla y León: 193-209.

SANCHES, M. J. 2017. Entre o ordinário e o extra-ordinário. Considerações sobre alguns lugares com arte rupestre de tradição esquemática do norte de Portugal. In: L. Rosas ; Ana C. Sousa \& H. Barreira, Genius Loci, Lugares e Signifcados (Places and Meanings), CITCEM: 281-304.

SANTONJA, M. 1998. Los tiempos prehistóricos. En: J. L. MARTín RodríGUEZ (ed.), Historia de Salamanca, Prehistoria y Edad Antigua, Vol 1, Salamanca, Centro de Estudios Salmantinos: 17-122.

SANTOS, A. T. 2015. Em torno da arte paleolítica do Vale do Côa. En: C. SANZ MíngueZ (ed.), El Bestiario vacceo. Vaccearte. $8^{\mathrm{a}}$ exposición de arte contemporáneo de inspiración vaccea, Valladolid: Ayuntamiento de Valladolid: 18-26.

SANTOS, A. T. 2017. A arte paleolitica ao ar livre da bacia do Douro à margem direita do Tejo: uma visão de conjunto. Tese realizada no âmbito do Doutoramento em Arqueologia. Faculdade de Letras da Universidade do Porto, Porto.

SAntos, A. T.; SAnches, M. J. \& TeIXeIRA, J. C. 2015. The Upper Palaeolithic rock art of Portugal in its Iberian context. In: P. BUENO \& P. G. BAHN (eds.), Prehistoric Art as Prehistoric Culture. Studies in Honour of Professor Rodrigo de Balbin-Behrmann. Archaeopress, Oxford: 123-134.

Santos, A. T.; Aubry, T.; Barbosa, A. F.; Garcia-DíEZ, M.; SAMPAIO, J. D. 2018. O final do ciclo gráfico paleolítico do Vale do Côa: A arte móvel do Fariseu (Muxagata, Vila Nova Foz Côa), Portvgalia, Nova Série, vol. 39, Porto, DCTP-FLUP: 5-96.

SAUVET, G. 2017. The lifeworld of hunter-gatherers and the concepts of territory. March, 2017, Quaternary International.

Slimak, L.; Fietzke, J.; Geneste, J.M. \& OnTAÑón, R 2018. Comment on "U-Th dating of carbonate crusts reveals Neandertal origin of Iberian cave art. Science, 361, eaau1371.

Silva, G. P.; Bardají, T.; Roquero, E.; Baena-Preysler, J.; Cearreta, A.; Rodríguez-Pascua, M.A; RoSAS, A.; ZAZO, C. \& GoY, J.L. 2017. El Periodo Cuaternario: La Historia Geológica de la Prehistoria Cuaternario y Geomorfología, Vol. 31, 3-4: 113-154. 
STEELMAN, K.; LOMBERA-HERMIDA, A.; VIÑAS-VALLVERDÚ, R.; RODRÍGUEZ-ÁlVAREZ，X.;CARRERA-RAMÍREZ, F.; Rubio-Mora, A. \& FÁbregas-Valcarce, R., 2017. Cova Eirós: An Integrated Approach to Dating the Earliest Known Cave Art in NW Iberia. Radiocarbon, 59 (1): 151-164.

Straus, L. 2018. El Paleolítico Superior de la península ibérica. Trabajos de Prehistoria, Vol. 75, n. 1: 9-51.

TeixeirA, J. C. \& SANChES, M. J. 2017. O abrigo rupestre da foz do rio Tua no contexto da arte paleolítica e pós-paleolítica do Noroeste da Península Ibérica. Porto, Portvgalia, 38: 9-48.

Tomasso, A.; Fat Cheung, C.; Fornage-Bontemps, S.; LANGlais, M. \& NAUdinot, M. 2018. Winter is coming: What happened in western European mountains between 12.9 and $12.6 \mathrm{ka}$ cal. BP (beginning of the GS1). Quaternary International, 465: 210-221.

Utrilla, P.; BALdelloU, V.; BEA, M. \& ViÑAs, R. 2012. La cueva de la Fuente del Trucho (Asque-Colungo, Huesca): Una cueva mayor del arte gravetiense. El Gravetiense Cantábrico, estado de la cuestión, Santillana del Mar, Monografias del Museo Nacional y Centro de Investigación de Altamira, 23: 526-537.

VÁZQUEZ MARCos, C. 2014. Análisis estadístico del caballo en el sitio de Siega Verde. En: M. S. CORCHÓN Y M. MENÉNDEZ (eds.), Cien años de arte rupestre paleolitico. Universidad de Salamanca, Salamanca: 273 283.

VÁZQUEZ MARCos, C. 2015. Análisis estadístico de las grafias figurativas zoomorfas de cabras grabadas en el sitio arqueológico de Siega Verde (Serranillo, Salamanca, España). En: H. COLlado Y J. GARCÍA ArRAnZ (eds.), Actas del XIX International Rock Art Conference IFRAO, Cáceres, ARKEOS, 37: 847 -862 .

VÁZQuez MARCos, C. 2017. Despieces ventrales “en M" en las representaciones peninsulares de équidos superopaleolíticos. Sautuola, XIX: 471-500.

VÁzquez Marcos, C. \& Reis, M. 2019. Arroyo de las Almas (La Fregeneda, Salamanca): un nuevo sitio con arte Paleolítico al aire libre. Trabajos de Prehistoria, Vol. 79, n. 1.
VÁzquez Marcos, C. \& Angulo Cuesta, J. p.p. Conoce Siega Verde. Arte Paleolitico al aire libre. XXXIII Premio de Investigación Julián Sánchez El Charro. Excmo. Ayuntamiento de Ciudad Rodrigo.

VIÑAs, R.; RuBIO, A. \& RuIz LÓPEZ, J. F. 2012. La técnica paleolítica del trazo fino y estriado entre los orígenes del estilo levantino de la Península Ibérica. Evidencias para una reflexión. In: J. CLOTTES (dir.), L'art pléistocène dans le monde / Pleistocene art of the world / Arte pleistoceno en el mundo, Actes du Congrès IFRAO, Tarascon-sur-Ariège, septembre 2010, Symposium «Art pléistocène en Europe». $\mathrm{N}^{\circ}$ spécial de Préhistoire, Art et Sociétés, Bulletin de la Société Préhistorique Ariège -Pyrénées, LXV-LXVI, 2010-2011, CD: 165-178.

VILlaVERDE, V. 2015. Palaeolithic art in the Iberian Mediterranean region. Characteristics and territorial variation, In: P. BuENO \& P. G. BAHN (eds.), Prehistoric Art as Prehistoric Culture. Studies in Honour of Professor Rodrigo de Balbin-Behrmann. Archaeopress, Oxford:145-155.

WelKer, W. 2016. First Palaeolithic rock art in Germany: engravings on Hunsrück slate. Antiquity,90, 349: 32 -47 .

Yravedra, J.; ANDrÉs-Chaín, M. ; Quesada, C.; MARTOS Romero, J.; MARQUer, L.; AVEZUEla, B.; JordÁ PARdo, J.; MARTín LeRMA, I.; SesÉ, C. \& VALDIVIA, J. 2018. Recurrent Magdalenian occupation in the interior of the Iberian Peninsula: new insights from the archaeological site of La Peña de Estebanvela (Segovia, Spain). Archaeological and Anthropological Sciences: 1-13.

ZILHÂO, J. 2003. Vers une chronologie plus fine du cycle ancien de l'art paléolithique de la Côa: quelques hypothèses de travail. En: R. DE BALBín \& P. BUENO (eds.), El Arte Prehistórico desde los inícios del siglo XXI, Ribadesella, Asociación Cultural Amigos de Ribadesella-Primer Symposium Internacional de Arte Prehistórico de Ribadesella: 75-90 